\title{
LAS IMPLICANCIAS JURÍDICAS DE LA NORMALIZACIÓN TÉCNICA. SUS ANTECEDENTES, PROYECCIÓN Y LAS MANIFESTACIONES PARA EL CASO DE CHILE
}

\section{CHRISTIAN Rojas CALDERÓN*}

RESUMEN: El autor explica en este trabajo, el origen y funcionamiento de la normalización o estandarización técnica a nivel internacional primero, luego revisando algunos ejemplos de Derecho extranjero y concluyendo con la situación en Chile; estableciendo a partir de lo anterior la vinculación entre normas técnicas y normas jurídicas y el modo en que se concreta esa relación a través de fórmulas remisivas utilizadas por el ordenamiento jurídico. Producto de ello se hacen presentes algunos problemas vinculados con dicha cuestión, sobre todo las relativas al control.

PALABRAS CLAVE: Normalización - normas técnicas - normas jurídicas - remisión normativa.

\section{THE JURIDICAL IMPLICATIONS OF THE TECHNICAL NORMALIZATION: BACKGROUND, PROJECTIONS AND HOW IT DISPLAYS IN THE CHILEAN CASE}

ABSTRACT: The author explains in this article the origin and functioning of the technical normalization or standardization, starting at an international level and then reviewing some examples of Law overseas. He concludes with the Chilean situation, where he establishes the connections between the technical and juridical norms and the manner in which that relationship is established through remission formulas used by the legal system. As a result, some problems arise related to the topic, mainly those related to control.

KEY WORDS: Normalization - technical norms - juridical norms normative remission.

Profesor Asistente de la Universidad Católica del Norte (CHILE). Magíster en Ciencia Jurídica por la P. Universidad Católica de Chile. Correo electrónico: chrojas@ucn.cl Fecha de recepción: 21 de julio de 2009.

Fecha de aprobación: 12 de agosto de 2009.

Abreviaturas: AENOR: Asociación Española de Normalización y Certificación; INN: Instituto Nacional de Normalización; ISO; International Organization for Standarization; NCh: Norma oficial chilena; RAP: Revista de Administración Pública. 
SUMARIO: Introducción. I.- Algunas cuestiones generales acerca de los procesos de normalización o estandarización de normas técnicas, a nivel internacional y en Chile. II.- Las concreciones de la normalización a nivel de los ordenamientos jurídicos. El caso de la Unión Europea, España, Alemania y México. III.- Una diferenciación necesaria: la distinción y vinculación entre normas técnicas y normas reglamentarias. IV.- Los procesos normogénicos de creación de normas técnicas en Chile y sus efectos jurídicos. Conclusiones. Bibliografia.

\section{INTRODUCCIÓN}

En este trabajo se pretenden entregar algunas nociones acerca del sistema de normas técnicas, dada la enorme vinculación entre esta clase de reglas y las propias del ordenamiento jurídico, que registra inmensas proyecciones, sobre todo hacia los ámbitos de la seguridad y la calidad en el ámbito industrial. A partir de lo anterior se explicará la íntima vinculación entre esas normas técnicas y las normas reglamentarias (de carácter estrictamente jurídico), se expondrá cómo funcionan los procesos generadores de dichas normas, para adicionalmente, revisar el sistema de normalización entre otros ámbitos en la Unión Europea, y se intentarán descifrar sus ventajas e inconvenientes. Enseguida, se pretende verificar la forma en que se realizan los procesos normogénicos en nuestro país en lo relativo a la seguridad y la calidad industrial, y con ello se intentará llenar un vacío en la dogmática que, hasta donde se ha revisado, no se ha hecho cargo de estas cuestiones. Finalizará este trabajo, con las conclusiones de rigor.

\section{1) Algunas CUESTIONES geNerales aCERCA DE LOS PROCESOS DE NORMALIZACIÓN O ESTANDARIZACIÓN DE NORMAS TÉCNICAS, A NI- VEL INTERNACIONAL Y EN CHILE}

\section{(1.1) El PROBLEMA DE LA NORMACIÓN DE LA COMPLEJIDAD TÉCNICA}

Resulta inobjetable la afirmación de la íntima conexión entre la técnica y el Derecho. En efecto, aunque se encuentren distanciados por la naturaleza de los saberes a que se vinculan -el primero a las ciencias naturales, y el segundo a las humanidades-, estos se encuentran conectados por la concreción de sus disposiciones.

Así, de la técnica surgen conocimientos de directa aplicación práctica o de reconocimiento en el mundo material, sea en un procedimiento, en una creación industrial, en una lex artis o regulae artis o un saber hacer. $\mathrm{Y}$ del Derecho, surge un universo normativo, que tiene por finalidad or- 
denar la sociedad y las relaciones entre los individuos de esta. Al fin, en ambos casos con finalidades eminentemente prácticas.

No obstante, en aquellas zonas del conocimiento donde los avances se suceden muy rápidamente -como en la biogenética, el medio ambiente, o las telecomunicaciones-, el Derecho va muy a la saga ${ }^{1}$. Y aquello se explica en gran medida por las distintas finalidades de uno y otro saber, y en el carácter habitualmente condicionado por la realidad de la ciencia jurídica en su proceso normativo. A ello ha de sumarse necesariamente, la imposibilidad técnica de las administraciones públicas para realizar un control del desarrollo tecnológico y de sus riesgos.

Sin embargo, este enorme y veloz progreso es en absoluto indiferente al Derecho, por lo que surge la necesidad - en la medida de sus medios o instrumentos- de tomar posiciones de control en puntos estratégicos a fin de evitar la desregulación de cuestiones tan sensibles como las ya señaladas. Aquello ocurre precisamente y se hace imperioso cuando la técnica genera riesgos ${ }^{2}$, y por tanto, donde existen intereses públicos comprometidos.

Esto se da, evidentemente, dentro del marco de una "sociedad de riesgo", que es aquella en donde debido a la acción del hombre se originan peligros que no tienen origen natural, sino que se han debido en último término a la decisión del hombre. Precisamente, las normas ante esta técnica, actúan como un instrumento de control de esos riesgos, y en efecto, el protagonismo de la técnica en las actividades productivas y especialmente las industriales, nos obliga a convivir con los riesgos generados por dichas actividades que tienen incidencia directa y diaria en la seguridad, salud y vida de las personas ${ }^{3}$.

Toda esta complejidad técnica que preside la reacción jurídica frente al riesgo, ilumina una nueva concepción de la intervención que rebasa sus formas tradicionales, generando nuevas soluciones jurídicas ${ }^{4}$. Ahora bien, esa clase de normas reguladoras es de tipo jurídico por lo general y, consiguientemente, de carácter obligatorio. Ejemplo de aquello se da fundamentalmente en el ámbito de la seguridad y en relación a ciertas actividades especialmente riesgosas -como la actividad minera, forestal, de pesca, o de construcción-, donde por vía legislativa -en términos generales- y luego por vía de reglamentos sectoriales -dependiendo del área específica-, se fijan las condiciones de realización de aquellas; mismas que son controladas directa o indirectamente por parte de la Administración

Esteve Pardo, J. (1999). Técnica, riesgo y Derecho. Barcelona: Ariel Derecho, p. 19.

Esteve (1999) 27.

Darnaculleta i Gardella, M. (2005). Autorregulación y Derecho Público: la autorregulación regulada. Madrid: Marcial Pons, p. 102.

Carrillo Donaire, J. A. (2009). "Seguridad y calidad productiva: de la intervención policial a la gestión de riesgos". RAP No 178 , p. 91. 
Pública -o las administraciones públicas en caso que sea algún órgano personificado, distinto de la Administración pública central-, a través de una redefinición de su actividad clásica de policía o intervención administrativa, caracterizada por una retirada o arrinconamiento de la misma con una correlativa "privatización" de la gestión del riego, donde más allá de una inicial colaboración de carácter instrumental, el Derecho ha terminado por reconocer efectos jurídico-públicos a las referencias técnicas generadas y a los controles ejercidos por sujetos privados especializados.

Así, se produce una identificación de conceptos: seguridad, obligatoriedad y reglamentos técnicos; de forma que un producto o una instalación es segura si cumple con las reglas técnicas contenidas en los reglamentos de seguridad. Y consecuencia de ello es que, como lo expresa Darnaculleta, "la asunción estatal de la responsabilidad de proteger la seguridad frente a los riegos generados por el desarrollo reduce, en un principio, las obligaciones de quienes generan tales riesgos al cumplimiento de las reglamentaciones técnicas de seguridad"5 que son impuestas por estos sujetos privados.

Esto ha ido produciendo -cada vez más y sin demasiado análisiseste fenómeno privatizador de funciones de control e inspección, o traslado, o delegación de esas funciones de modo más o menos inorgánico. Ejemplo claro de aquello, se encuentra en las "plantas de revisión técnica automotriz", que certifican -en nombre del Ministerio de Transportes y Telecomunicaciones y basados en un reglamento-, el cumplimiento de los requisitos técnicos para desplazarse por las calles y caminos en vehículos motorizados ${ }^{6}$; o también la gestión y auditoría medioambiental realizada por empresas certificadoras. Con ello se produce el efecto de preterir al encargado original de la tutela de los intereses públicos.

En este, como en muchos otros casos -empresas u organismos de control, certificadores ambientales, y entidades de acreditación-, se destaca que son actividades ejercidas por privados que realizan inequívocas funciones públicas; $y$, además, se encuentran integrados sistémicamente a una sucesión de habilitaciones donde los mayores autorizan a los intermedios y estos a los inferiores para ejercer sus funciones?

La respuesta a la pregunta del por qué de este fenómeno, se encuentra en general en el hecho cierto de la incapacidad material de una Administración Pública desbordada por el desarrollo tecnológico, ya no solo por su amplitud, sino que también por la complejidad que registra en muchos frentes y que exige para su control, una capacitación y conocimientos que no siempre se encuentran en su personal y en sus medios ${ }^{8}$.

Darnaculleta (2005) 103.

Reglamentado por Decreto MTT No 156 de 1990.

EsteVe (1999) 139-140.

8 Esteve (1999) 66. 


\section{Lo anterior supone también aceptar dos cuestiones:}

(a) La semisoberanía estatal, frente a organizaciones y corporaciones de ámbito supranacional; y

(b) La incapacidad de la ley para reflejar el dinamismo social y los avances tecnológicos.

No es que con lo anterior se pretenda entregar todo al mercado, sino que desde el reconocimiento de esas dos realidades es posible regular adecuadamente y con los instrumentos eficaces que se proveen por el Derecho, cuestiones tan delicadas como la de la especie, allí en donde se encuentre comprometido el interés público y del colectivo.

Es de esta forma que se explica la presencia de estos colaboradores, que escapan a los esquemas tradicionales que no logran dar respuestas adecuadas a este fenómeno colaborativo en los ámbitos tan sensibles como los destacados $-\mathrm{o}$, lo que es lo mismo, al ejercicio privado de funciones públicas ${ }^{9}$ - las más de las veces sin sujeción alguna a controles estatales.

Sin perjuicio de ello, lo cierto es que estos entes existen y desarrollan una intensa y muy valorada actividad, fundamentalmente en el ámbito del control de la aplicación de reglamentaciones técnicas por parte de laboratorios privados de ensayo o entidades colaboradoras en el ámbito de la inspección y verificación industrial, y lo mismo puede decirse respecto de la participación privada en el proceso de aprobación de reglamentaciones técnicas ${ }^{10}$.

En este contexto, la comunidad científica y técnica -al servicio en ambos casos de la industria y el desarrollo de los países-, progresivamente se ha ido autoorganizando, derivando consecuencialmente que las reglas técnicas aplicadas a determinados productos sean las mismas a nivel nacional e internacional. Si bien esto tuvo su origen en la racionalización y armonización de reglas técnicas en miras de un interés comercial (para facilitar su intercambiabilidad, y para allanar su venta producto de una diferenciación de los bienes en el mercado); progresivamente fueron adicionando el interés en la mejora de las características de los productos y/o servicios, en suma de su calidad como concepto vinculado a algunas características específicas o al cumplimiento de exigencias de seguridad ${ }^{11}$.

Fernández García, A. (2005). Participación y colaboración ciudadana en la Administración agraria. Madrid: INAP, pp. 64-65. Sobre la categoría del ejercicio privado de funciones públicas puede verse un desarrollo de la misma en: Rojas CALDERón, C. (2008). "Los organismos autónomos y la Administración del Estado". En Cordero Quinzacara, E. (Coordinador) Estudios sobre la Ley Orgánica Constitucional de Bases Generales de la Administración del Estado. Santiago: Universidad de Antofagasta, pp. 147-151.

10 Instituto Nacional de Normalización. Flujograma de estudio de norma técnica en el INN. Disponible en http://www3.inn.cl/normalizacion/estudio/portada/index.php [20 de diciembre de 2007]

11 Darnaculleta (2005) 104-105. 
Ante esta realidad surgen distintas fórmulas, una de las cuales es precisamente la que analizamos en seguida.

\section{(1.2) LA RESPUESTA DESDE LA NORMALIZACIÓN}

\section{(1.2.1) La normalización industrial}

En general puede definirse a la NORMALIZACIÓN (o estandarización) como el proceso destinado a la elaboración de unos elementos de referencia comunes para ordenar los diferentes comportamientos o actividades que se presentan de manera repetitiva en las relaciones sociales. Y luego, acercándonos a nuestro objeto, diremos que la NORMALIZACIÓN INDUSTRIAL es el proceso destinado al establecimiento de las normas que rigen la vida industrial, en tanto parámetros o criterios que deben ser respetados por los productos o sus fabricantes para poder ocupar un sitio en el mercado $^{12}$.

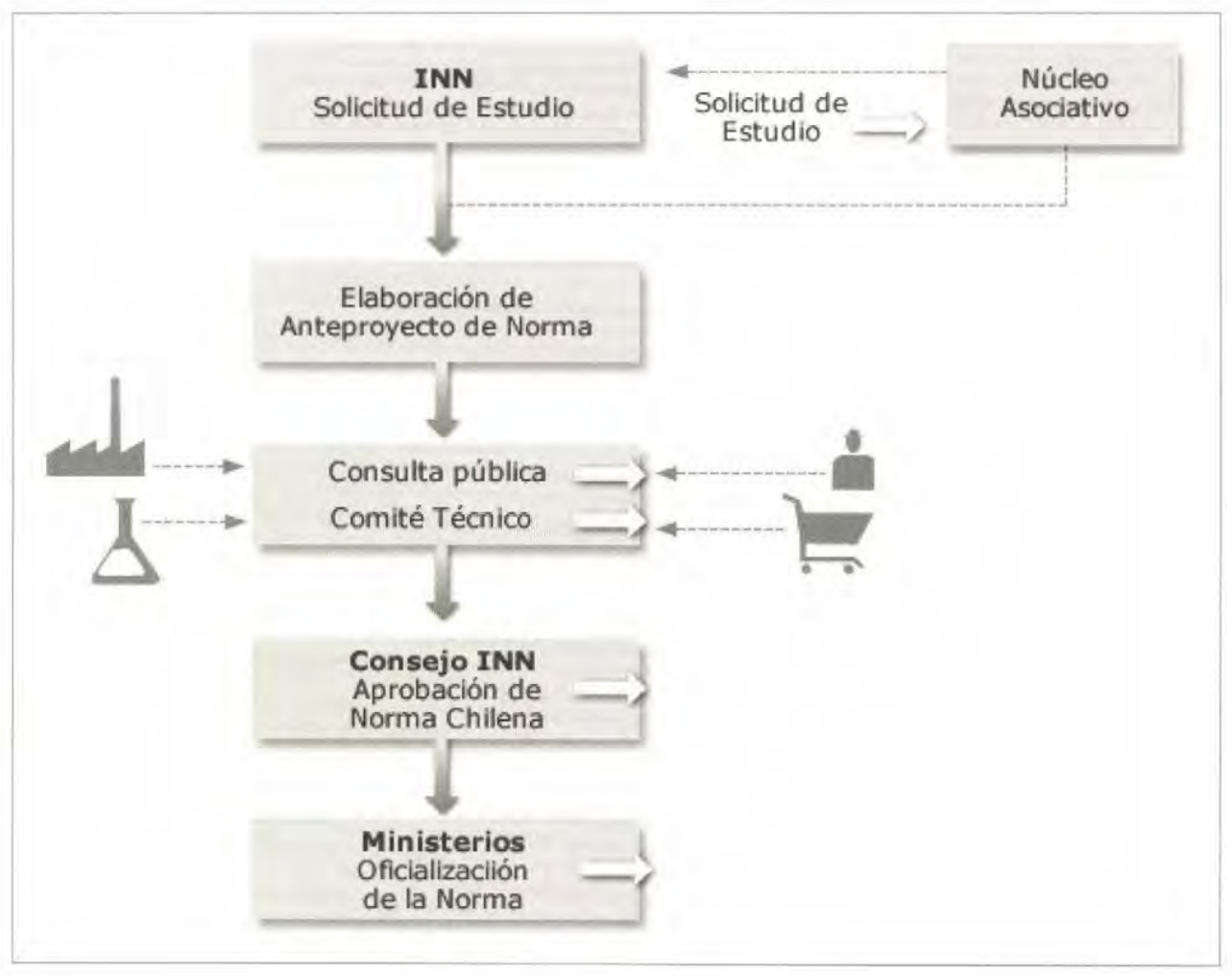

\footnotetext{
12 Álvarez García, V. (1998) "Introducción a los problemas jurídicos de la normalización industrial: normalización industrial y sistema de fuentes". RAP No 147, p. 311.
} 
Enseguida, a partir de la complejidad ya analizada previamente -especialmente surgida a partir del control de la calidad, vinculado con la actividad técnica o industrial-, es posible afirmar que han surgido respuestas que intentan hacer frente a una actividad en donde existen intereses públicos comprometidos, ya ejemplificados. Estas respuestas pueden agruparse en tres tipos: a) regulación jurídica y control directo por la Administración Pública, b) regulación jurídica y control realizado por particulares, c) y normalización. Bien se sabe, esta última alternativa es la fórmula en que los países más desarrollados han dado respuesta a las dinámicas y complejidades planteadas por la seguridad y calidad.

Y la normalización encuentra su expresión más fiel en la NORMA $T E ́ C N I C A^{13}$, y por ella hemos de entender una especificación técnica, que adquiere valor "normativo" en el ámbito normalizador. A su vez, las normas técnicas son susceptibles de clasificación, y según su origen se pueden distinguir entre normas internacionales y normas nacionales.

En virtud de ello es posible realizar una diferenciación que tiene claros efectos en la situación analizada, sobre todo con respecto a la actividad de NORMALIZACIÓN INDUSTRIAL, la que consistía originalmente y de manera exclusiva, en la armonización de procesos productivos mediante la unificación de criterios y tipificación de estándares técnicos que permitieran la compatibilidad física y la especificación de las cualidades de los productos industriales y de sus componentes ${ }^{14}$. En efecto, la normalización industrial surgió como una actividad completamente privada y completamente ajena al aparato orgánico administrativo, que fue cobrando relevancia en un mercado cada vez más pujante y hoy globalizado.

Sin perjuicio de lo anterior, a pesar de esa naturaleza privada -tanto por sus actores como por las cuestiones que le dieron origen, basadas en la compatibilidad de componentes de piezas industriales-; se ha ido experimentando un progresivo acercamiento a intereses públicos, sobre todo atendidas las finalidades a que se encuentra vinculada. Esto ha generado también, un progresivo interés por regular públicamente dicha actividad $y$, por ello, un acercamiento a la consideración de esta actividad como el ejercicio de una función pública.

Lo anterior, dados los intereses y ventajas de este proceso, se producen en una triple dimensión:

- En relación a los fabricantes: En la medida que la normalización constituye la condición para el paso de una producción artesanal a una en masa; posibilita la reducción de tiempo en los procesos in-

\footnotetext{
13 Tarrés Vives, M. (2003a). Normas técnicas y ordenamiento juridico. Valencia: Tirant lo Blanch, p. 232.

14 Carrillo Donaire, J. A. (2000). El Derecho de la seguridad y de la calidad industrial. Madrid: Marcial Pons, p. 67.
} 
dustriales; permite la reducción de la variedad inútil de productos; y contribuye a fortalecer el prestigio de la empresa "que fabrica conforme a normas" así como la reputación de sus productos.

- En relación a los consumidores o usuarios: En la medida que las normas, al fijar niveles de seguridad y calidad contribuyen a protegerlos; facilitan mayor información sobre el producto y/o empresa; y al incentivar la producción en masa generan economías de escala, lo que hace productos más baratos en su adquisición.

- En relación al interés general, cuya protección está encomendada a los poderes públicos: En la medida que la normalización cumple numerosos objetivos como constituir un mecanismo para la política industrial; permite conseguir una gestión racional de materias primas; contribuye al desarrollo tecnológico; posibilita la promoción de la seguridad y salud de los ciudadanos, la protección del medio ambiente y el desarrollo de la calidad de los productos industriales asegurando una progresiva mejora en la calidad de vida de las personas; contribuye a la simplificación de las relaciones económicas o comerciales internacionales al promover la utilización de un lenguaje común, así como bases contractuales y de referencias técnicas comunes; en fin, facilita la tarea de elaboración normativa de los poderes públicos, a partir de la labor realizada a propósito de normas técnicas $^{15}$.

Así, la NORMALIZACIÓN es un objetivo primordial de los poderes públicos en tanto medio en virtud del cual se accede a un instrumento que permite la defensa medioambiental, la protección de la salud, la seguridad, el derecho de los consumidores, y el fomento de la actividad industrial de calidad ${ }^{16}$.

Tradicionalmente, por el distinto ámbito de actuación de cada una de ellas, se distingue entre: normas de seguridad y normas de calidad, mismas que se pasan a revisar a continuación.

\section{(1.2.2) Las proyecciones a la seguridad y a la calidad}

(a) Las normas de seguridad

Atienden al ámbito de la SEGURIDAD INDUSTRIAL, concebida como aquella actividad que tiene por objeto la prevención y limitación de riesgos, así como la protección de accidentes y siniestros capaces de producir daños y perjuicios a las personas, flora, fauna, bienes o medio ambiente, 
derivados de cualquier fase de la actividad industrial. Se trata en efecto de un campo muy amplio, cuyas especificaciones deben desarrollarse en la normativa de cada sector o industria ${ }^{17}$.

Dichas normas tienden a regular la actividad dirigida a la prevención de los dańos y la protección contra los riesgos potenciales que comprende la utilización de los productos y el funcionamiento de las instalaciones industriales; $y$ tiene por finalidad limitar las causas que originan dichos riesgos y establecer los oportunos controles e inspecciones que permitan prevenir, detectar y, en su caso, evitar las circunstancias que pudieran dar lugar a la aparición de tales riesgos. Ejemplo de ello se encuentra en el etiquetado de especificaciones alimenticias o farmacéuticas, y las normas de seguridad en la construcción de inmuebles.

En dicha virtud, la normación de la seguridad industrial, comprende la regulación pública de determinados aspectos relativos a la producción industrial, y que juega un papel fundamental en orden a asegurar la regularidad y normalidad de dicha actividades ${ }^{18}$.

$\mathrm{Y}$ el instrumento más adecuado asegurar el cumplimiento de las condiciones de seguridad, aparte de los incentivos como subvenciones o fomentos estatales en general, se encuentra en un catálogo de infracciones administrativas normalmente presente en este tipo de regulaciones, no solo de tipo pecuniaria, sino también la pérdida de derecho a apoyos estatales o incluso el cierre temporal o definitivo del establecimiento industrial de que se trate ${ }^{19}$.

\section{(b) Las normas de calidad}

Atienden a la CALIDAD INDUSTRIAL, concebida como aquella actividad que trata de conseguir la continua mejora de los procesos industriales, en miras de la mayor adecuación posible entre sus propiedades, características y las necesidades que pretenden satisfacer ${ }^{20}$.

Esta clase de normas se vincula a la progresiva concurrencia e internacionalización de los mercados, la mejora de la competitividad de las empresas, y las progresivas exigencias de calidad por parte de los receptores finales de los productos; y en tal sentido el concepto de calidad se ha convertido en un crisol de confluencia de la excelencia productiva que, al mismo tiempo, se transforma en un factor diferenciador en el mercado.

PADrós ReIG, C. (2001). Actividad administrativa y entidades colaboradoras. Madrid: Tecnos, pp. 59-60.

18 Carrillo (2000) 25.

19 Bermejo Vera, J. et al. (2005). Derecho Administrativo. Parte especial. Cizur Menor: Thomson-Civitas, p. 973.

20 Bermejo (2005) 973-974.
} 
Desde el punto de vista de la técnica jurídica, la calidad industrial se asienta sobre la base de dos instrumentos: la normalización y la certificación; y sobre un principio básico: la voluntariedad de su cumplimiento. Ambos aspectos, importan actividades complementarias e inescindibles.

La normalización y la certificación de calidad son actividades utilizadas en casi todos los ámbitos de la vida económica y ello, es considerado hoy, dentro de las inversiones que debe realizar una empresa y ya no un gasto. Así tanto la supervivencia de una empresa, como la posible incorporación a nuevos mercados en el ámbito de una economía comercialmente abierta, está ligada a la mejora de su competitividad mediante la implantación de técnicas de calidad industrial; y, por ello, la normalización industrial y la certificación voluntaria son elementos imprescindibles en el sistema industrial competitivo como el nuestro ${ }^{21}$.

Por consiguiente, en este ámbito, donde la normalización se concreta en el establecimiento de documentos de referencia que aporten soluciones a problemas no solo técnicos, sino que también comerciales que conciernen a productos, bienes y servicios en las relaciones entre los agentes económicos, científicos y sociales $^{22}$; se hace preciso, enseguida, que se certifique o compruebe la sujeción de dichos sistemas, procesos, equipos y productos a los requisitos y especificaciones técnicas referenciales de calidad, establecidos en normas técnicas voluntarias, llevado a cabo por una entidad independiente, cuya competencia técnica acreditadora ha sido previamente habilitada.

\section{(1.3) LA INTERNATIONAL ORGANIZATION FOR STANDARIZATION (ISO), Y EL INSTITUTO NACIONAL DE NORMALIZACIÓN (INN) PARA EL CASO DE CHILE}

Todo lo visto se realiza en un contexto internacional por una necesidad, lo que tiene una correspondencia nacional aplicable a nuestro caso, $y$ que se pasan a revisar sucintamente.

\section{(1.3.1) La ISO}

A nivel internacional y con carácter supranacional, destaca en este ámbito y de entre las organizaciones privadas la International Organization for Standarization (ISO).

Como se sabe, a poco andar del siglo XX, un conjunto de organizaciones privadas se estructuraron a partir de un modelo multisectorial y centralizado, a fin de construir una asociación internacional que reagru-

TARRÉS (2003a) 231. 
pase y ordenase las distintas organizaciones nacionales que actuaban multisectorialmente, con la finalidad de unificar y transparentar el comercio a través de la estandarización o normalización de las características de los bienes a fin de asegurar su compatibilidad ${ }^{23}$, y que al poco andar devino en nuevas cuestiones, como la seguridad y la calidad.

La Organización Internacional para la Estandarización o International Organization for Standarization (ISO), nace en 1947 -teniendo como antecedente la International Standarizing Association (ISA) fundada a su vez en 1930-, a partir en la cumbre internacional celebrada en Londres en 1946. Desde ese momento, la ISO es el organismo encargado de promover el desarrollo de normas internacionales de fabricación, comercio y comunicación para todas las ramas industriales a excepción de la eléctrica y la electrónica. Su función principal es la de buscar la estandarización de normas de productos y seguridad para las empresas u organizaciones a nivel internacional.

Hoy, la ISO es una red de los institutos de normas nacionales de 157 miembros -sobre la base de un miembro por el país-, con una Secretaría Central en Ginebra (Suiza), que coordina el sistema. Está compuesta por delegaciones gubernamentales y no gubernamentales subdivididos en una serie de subcomités encargados de desarrollar las guías que contribuirán al mejoramiento ambiental. Las normas desarrolladas por ISO son voluntarias, comprendiendo que ella es un organismo no gubernamental y no depende de ningún otro organismo internacional, por lo tanto, no tiene autoridad para imponer sus normas a ningún país ${ }^{24}$.

En sus aspectos constitutivos, se trata de una organización internacional no gubernamental, compuesta por representantes de los organismos de normalización nacionales, que produce normas internacionales industriales y comerciales. Dichas normas se conocen como Normas ISO y su finalidad es la coordinación de las normas nacionales, en consonancia con el Acta Final de la Organización Mundial de Comercio, con el propósito de facilitar el comercio, facilitar el intercambio de información y contribuir con unos estándares comunes para el desarrollo y transferencia de tecnologías.

La organización ISO está compuesta por tres tipos de miembros:

- Miembros natos: uno por país, recayendo la representación en el organismo nacional más representativo.

- Miembros correspondientes: de los organismos de países en vías de desarrollo y que todavía no poseen un comité nacional de normalización. No toman parte activa en el proceso de normalización pero están puntualmente informados acerca de los trabajos que les interesen.

24 Nace como organización no gubernamental, con forma de asociación de Derecho privado, constituida y regulada conforme el Código Civil suizo y que entró oficialmente en funcionamiento el 23 de febrero de 1947. 
- Miembros suscritos: países con reducidas economías a los que se les exige el pago de tasas menores que a los correspondientes.

La ISO, adicionalmente, es un órgano consultivo de la ONU y, además, coopera estrechamente con la CEI (International Electrotechnical Commission, IEC) que es responsable de la estandarización o normalización de equipos eléctricos.

Su sigla -ISO- no es un acrónimo, sino que proviene del griego iso, que significa igual. Es un error común el pensar que ISO significa International Standards Organization, o algo similar; en inglés su nombre es International Organization for Standarization, mientras que en francés se denomina Organisation International de Normalisation; el uso del acrónimo conduciría a nombres distintos: IOS en inglés y OIN en francés, por lo que los fundadores de la organización eligieron ISO como la forma corta y universal para su nombre.

Los trabajos de la ISO se desarrollan a través de órganos técnicos de normalización integrados en el "Bureau" de Gestión Técnica de la ISO, especializados en distintos sectores productivos que actúan bajo la coordinación de la Secretaría Central de la ISO ${ }^{25}$.

\section{(1.3.2) $\mathrm{El} \mathrm{INN}^{26}$}

La organización antes vista, reconoce en el InSTITUTO NACiONAL de Normalización, para el caso de Chile, su correspondiente oficial en nuestro país, el que actúa como "miembro nato" o "member body" de acuerdo a la categoría recién explicada ${ }^{27}$.

Los miembros de esta organización, entre ellos el INN, no están obligados a trasponer esas normas en su ordenamiento normalizador nacional; es más, la aprobación de una norma ISO no impide, ni el mantenimiento, ni la adopción de nuevas normas nacionales, parcial o totalmente divergentes $^{28}$. No obstante, con carácter general, las normas ISO acostumbran a ser adoptadas y traducidas por los organismos regionales o nacionales. Esto se explica por la voluntariedad, que se encuentra en el origen de la institución.

\footnotetext{
25 Carrillo (2000) 74 .

26 Instituto Nacional de Normalización (2004). Calidad un proyecto pais. Santiago: autoedición, pp. 8-14. Disponible en http://www3.inn.cl/pdfs/docinstitucionales/memoria2004.pdf [14 de noviembre de 2007].

27 International Organization for Standarization (ISO) "ISO members". Disponible en: http://www.iso.org/iso/about/iso_members/iso_member_body.htm? member_id=1629 [fecha de consulta 21 de diciembre de 2007] 
El INN es una fundación de Derecho privado creada por CORFO ${ }^{29}$ y constituye un organismo técnico, sin fines de lucro, que contribuye al desarrollo productivo del país fomentando el uso de la metrología y de las normas técnicas por parte de entidades públicas y privadas, y acreditando a las empresas y organismos de certificación. En julio de 1986, el Decreto 533 del Ministerio de Justicia modificó sus estatutos, lo que significó que los miembros del Consejo dejaran de realizar sus funciones ad honorem y que fuera incorporada entre sus actividades la administración de un Sistema Nacional de Certificación de Conformidad. Por otro lado, el INN obtuvo ese mismo año la calidad de Instituto de Investigación del Estado.

En Chile, es parte del Sistema Nacional de Calidad y, en el concierto mundial, representa al país ante la ISO, principal ente normalizador internacional de la que es fundador. Su misión consiste en apoyar al sistema productivo nacional y a los distintos agentes del mercado, en sus esfuerzos por mejorar la calidad de los productos y servicios existentes en el país, por la vía de un mayor uso de la normalización técnica, la evaluación de la conformidad y la metrología.

Para cumplir dicha tarea el INN se ha planteado los siguientes objetivos estratégicos:

- Facilitar y promover el uso de normas técnicas -acordes con criterios internacionales- en el sistema productivo nacional e incentivar la participación de los usuarios en el desarrollo de las mismas.

- Promover y administrar un sistema nacional de acreditación, que dé mayor credibilidad a las actividades de evaluación de la conformidad realizadas en el país.

- Coordinar y supervisar una red chilena de metrología, destinada a incorporar exactitud y precisión en las mediciones que realiza el sistema productivo nacional y darles trazabilidad con reconocimiento internacional.

- Difundir y promover el uso de las materias señaladas, ofreciendo especializados servicios de capacitación y documentación.

Dichos objetivos se expresan en la generación de normas técnicas chilenas, acordes a los criterios internacionales; en la administración del Sistema Nacional de Acreditación; en la coordinación y administración de la Red Nacional de Metrología; en la capacitación por la vía de realizar cursos, seminarios y diplomados; en la disponibilidad de un servicio de malización, acreditación y metrología, de modo de ofrecer a las empresas instrumentos para impulsar el control de calidad. 
documentación abierto al público, y en la participación en seminarios y exposiciones sobre las materias pertinentes al Instituto.

El INN está estructurado en torno a seis divisiones, a saber:

(a) División de Normas

Que detecta las necesidades de nuevas normas y, siguiendo un procedimiento riguroso y participativo -basado en criterios internacionales-, llega a la elaboración de textos que, luego de aprobados por el Instituto, son oficializados por los respectivos ministerios nacionales.

(b) División de Acreditación

En esta área radica el Sistema Nacional de Acreditación, por el que el INN, como autoridad técnica, reconoce formalmente que una organización es competente para efectuar actividades específicas de evaluación de la conformidad.

(c) División de Metrología

Su función primordial es la de coordinar la Red Nacional de Metrología y administrar sus recursos. Coordina y supervisa los Laboratorios Custodios de los Patrones Nacionales y tiene a su cargo las relaciones con agencias y ministerios del Gobierno de Chile y la participación internacional en esta área

(d) División de Difusión y Capacitación

Su objetivo es apoyar a los sectores productivos en el conocimiento y aplicación de las normas de calidad, ofreciendo a las empresas acceso a programas de capacitación; un eficiente Centro de Documentación; información actualizada a través de una página web (www.inn.cl) y a la adquisición de normas chilenas individuales o compendiadas sectorialmente.

(e) División de Desarrollo

Abocada a implementar y administrar los Registros de Consultores y Organismos de Certificación del INN, en conjunto con CORFO. Cuenta con una Unidad de Registro encargada de evaluar los antecedentes profesionales, comerciales y de experiencia de los postulantes al Registro de Consultores, mediante la revisión de antecedentes y la elaboración y aplicación de un instrumento de evaluación de conocimientos. Además de verificar los certificados emitidos por los Organismos de Certificación pertenecientes al Registro. 
Estas divisiones, más la destinada a Administración y Finanzas, forman una institución que hoy cuenta con una planta de 70 personas encabezada por un Director Ejecutivo designado por el Consejo del INN a propuesta de su presidente. A su vez, este consejo está compuesto por miembros designados por CORFO.

Por cierto, este instituto del Estado (en realidad de la Administración del Estado) -por su vinculación a CORFO- se relaciona directamente con el Ministerio de Economía ${ }^{30}$.

\section{2) LAS CONCRECIONES DE LA NORMALIZACIÓN A NIVEL DE LOS ORDENAMIENTOS JURÍDICOS. EL CASO DE LA UNIÓN EUROPEA, ESPAÑA Y MÉXICO}

Frente a la realidad y contextos ya descritos, el Derecho no es indiferente y debe reivindicar el poder racionalizador de las relaciones entre la técnica y el riesgo o calidad, que le ha sido entregado, para que el orden público no vea hurtado su protagonismo directivo. Esto mismo lleva al Derecho a tomar decisiones y realizar distinciones a fin de reconocer, valorar y gestionar las áreas de interés público comprometidos en ello ${ }^{31}$.

En virtud de lo primero, regulará el derecho-deber de información, fijará procedimientos y garantías para su reconocimiento. Por lo segundo, debe decidir qué riesgos se asumen y cuáles se rechazan por medio de conceptualizaciones pertinentes (como "seguridad" o "calidad"), lo que las llevará a apreciar científicamente considerando el estado de los conocimientos. Y en virtud de lo tercero, se deberá decidir cuáles son las medidas de protección o de reacción que deben tomarse en un caso determinado.

Con esta misma perspectiva, se pasará a revisar la regulación de los casos indicados en el título.

\section{(2.1) La NORMALIZACIÓN Y CERTIFICACIÓN. EL CASO DE LA UNióN EUROPEA}

\section{(2.1.1) Aspectos generales}

A fin de explicar adecuadamente -para los objetos de esta investigación-, las condiciones y supuestos de operación de la seguridad y la calidad industrial; se revisará en esta parte el régimen regulatorio de dichas partir del complejo de personas jurídicas que la forman, y en esta clasificación reconocía claramente a los denominados "institutos". Soto Kıoss, E. (1986). "La organización de la Administración del Estado. Un complejo de personas jurídicas". Gaceta Juridica No 73, p. 21. 
actividades a nivel de la Unión Europea, asimilable a todos sus miembros que hoy suman ya 27 países, teniendo 3 más como candidatos ${ }^{32}$.

Comprobado el fracaso de la armonización completa y total de las legislaciones en el marco de la UE, se produce un cambio que se materializó en dos decisiones. En primer lugar, la aprobación por el Consejo, de la Directiva 85/189/CEE mediante la cual se establece un procedimiento de información en materia de normas y reglamentaciones técnicas, y obliga a los Estados miembros a respetar un plazo de statu quo, antes de poner en vigor las normas y reglamentaciones técnicas a nivel nacional. Y en segundo lugar, constituye hito fundamental en este tema la adopción por parte del Consejo de la UE de un "NUEVO ENFOQUE" 33 en materia de armonización y normalización técnica, realizada por medio de Resolución $85 / \mathrm{C} / 136 / 81$ de 7 de mayo de $1985^{34}$.

Como se ha sostenido, originalmente la normalización respondía a la necesidad de regular y homogeneizar cuestiones de carácter metrológico, cualitativo y técnico sobre productos con el objeto de facilitar su intercambiabilidad en miras de su comercialización; pero luego, fueron los procesos industriales de elaboración de esos productos y los controles de tales procesos, así como la seguridad en los mismos y calidad de los sujetos encargados el objeto de ella. De este modo, las normas técnicas pasan a perseguir ya no solo la intercambiabilidad de los productos y su calidad, sino que también la seguridad de los mismos y la minimización de los riesgos derivados de los procesos de producción.

\section{(2.1.2) El "nuevo enfoque"}

Fracasado el proceso de armonización en detalle y la reglamentación administrativa de esta temática, surge el aludido "nuevo enfoque". Este se contiene en cuatro principios fundamentales, a saber: en primer lugar, se pretende que la armonización comunitaria en materia de seguridad industrial se limite a la adopción de las exigencias esenciales de seguridad; estas deben ser respetadas por todos los productos puestos en el mercado, los cuales, por ese hecho se benefician de la libre circulación en la Comunidad; en segundo lugar, las mencionadas exigencias esenciales de seguridad sean especificadas y desarrolladas, teniendo en cuenta el estado de la tecnología, por los organismos competentes en materia de normalización industrial; en tercer lugar, las especificaciones técnicas aprobadas por los organismos de normalización no tendrán carácter obligatorio,

Europa. El portal de la Unión Europea (s/d). Estados miembros de la Unión Europea. Disponible en http://europa.eu/abc/european_countries/index_es.htm [20 de diciembre de 2007]

33 Sobre el cual, puede verse el detalle en Carrillo (2000) 262-283.

34 ÁllVArEz (1998) 313. 
conservando su estatuto de normas voluntarias; y por último, en cuarto lugar, a pesar del carácter voluntario de las normas técnicas armonizadas, se obliga a las administraciones públicas a reconocer en los productos fabricados en conformidad a las mismas, una presunción de conformidad con las exigencias esenciales que fijan las condiciones; de forma tal que las empresas tienen la facultad de no sujetar la fabricación de sus productos a las normas voluntarias señaladas, pero en ese caso -no siendo beneficiados por la presunción de "conformidad"- deberán probar que cumplen con las exigencias establecidas en tales normas ${ }^{35}$.

Este nuevo enfoque se concreta con la aprobación de la Resolución del Consejo de 21 de diciembre de 1989, relativa a un planteamiento global en materia de evaluación de conformidad, llamada "ENFOQUE GLOBAL".

Para que este sistema funcione, es necesario que existan en los Estados organismos acreditados que certifiquen la conformidad de los productos de las normas técnicas armonizadas; y, además, que se indique cuáles son los organismos competentes en materia de normalización.

\section{(2.1.3) Los organismos europeos de normalización}

A nivel europeo se han creado organizaciones privadas que cumplen estas funciones. En efecto, existen tres organismos de normalización que tiene la forma jurídica de asociaciones privadas sin fines de lucro como son el Comité Europeo de Normalización (CEN), el Comité Europeo de Normalización Electrotécnica (CENELEC) y el Instituto Europeo de Normas de Telecomunicaciones (ETSI). Se suma a ello, recientemente la Organización Europea de Certificación (EOTC).

Todo lo dicho proviene del "nuevo enfoque" a que ya se ha hecho referencia. A través de ello, se refuerza la importancia de la normalización en la seguridad y en la calidad industrial a través de la ampliación de los fines y contenidos de la normalización, y a través de la obligatoriedad de facto de las normas técnicas impuestas por la normativa comunitaria $^{36}$.

\section{(2.1.4) Las normas técnicas europeas armonizadas y su adopción por los sistemas nacionales de normalización}

La correcta aplicación de este "nuevo enfoque" pasa por el desarrollo de normas técnicas armonizadas a nivel europeo, que son elaboradas por los organismos europeos de normalización competentes para cada caso, ya señalados. 
Enseguida, es posible afirmar que la elaboración de normas técnicas armonizadas europeas se fundamenta en los mandatos que la Comisión dirige a los organismos europeos de normalización para la adopción de aquellas. Los mandatos son actos unilaterales de la comisión adoptados en el marco del contrato marco de cooperación celebrado por la Comisión y los organismos europeos de normalización de 1985, a través de los cuales se les invita en razón de la materia, a elaborar y presentar ante ella normas técnicas armonizadas, cuyo título y referencia habrán de ser posteriormente publicadas por la Comisión.

Luego, las normas técnicas europeas se clasifican en razón del consenso que las entidades nacionales de armonización alcanzan en el seno de las entidades nacionales de normalización, y el grado de compromiso que estos adquieren en orden a su transposición a los sistemas nacionales de normalización. Por ello se distingue entre los siguientes ${ }^{37}$ :

\section{(a) Normas europeas (EN)}

Son adoptadas por el consenso de todos los comités miembros (entidades nacionales de normalización). Recae sobre ellos la obligación de trasponer las normas europeas de la serie EN a los sistemas internos de normalización, mediante su conversión en normas técnicas nacionales.

\section{(b) Documentos armonizados (HD)}

Que también han de ser obligatoriamente traspuestos en los sistemas internos de normalización por los "comités miembros" e, igualmente, estos no podrán adoptar normas técnicas en los sectores sobre los que existe un documento armonizado.

Sin embargo, en este caso, los "comités miembros" pueden presentar divergencias nacionales a la hora de trasponer los documentos armonizados a sus sistemas internos de normalización, que se pueden deber a reglamentaciones comerciales internas o a razones técnicas que aconsejan mantener un período de transición hasta su aplicación.

\section{(c) "Prenormas" europeas (ENV)}

Estas son normas prospectivas de aplicación provisional, durante un período de tiempo (tres años prorrogables por dos más).

Estas "prenormas" se elaboran para ámbitos en donde existe un alto grado de innovación técnica (por ejemplo, en ámbito de las telecomunicaciones) y en los que la seguridad de las personas o los bienes no resulta 
comprometida. Se trata así, de normas de carácter experimental que en el futuro pueden llegar a ser normas se la serie EN.

Finalmente, debe destacarse que la trasposición de normas europeas armonizadas -principalmente las de la serie EN-, en los sistemas nacionales de normalización industrial, se erige como un elemento esencial para la consecución de los objetivos trazados del "nuevo enfoque", ya explicados.

\section{(2.2) LA ACREDITACIÓN DE LA SEGURIDAD Y CALIDAD INDUSTRIAL. EL CASO DE ESPAÑA}

\section{(2.2.1) Cuestiones generales ${ }^{38}$}

Los inicios de la normalización en Espańa van ligados al sector de la electricidad. Por RD de 22 de noviembre de 1912 se creó en el seno del entonces Ministerio de Fomento, la Comisión Permanente Española de Electricidad. El artículo 4 de este encomendaba a dicho organismo la representación española en el seno de la Comisión Electrotécnica Internacional.

Habrá que esperar al año 1935 cuando se creó, a iniciativa de la Federación de Industrias Nacionales, el primer organismo multisectorial de normalización denominado "Asociación Española de Normalización". Sin embargo, este primer intento resultó fallido debido al estallido de la Guerra Civil (1936-1939). Solo una década más tarde y en un escenario claramente autárquico se establece en 1946, el Instituto de Racionalización del Trabajo (IRATRA). El IRATRA se convierte en 1971 en el IRANOR (Instituto Español de Racionalización y Normalización), organismo adscrito al Consejo Superior de Investigaciones Científicas y, a su vez, dependiente del Ministerio de Educación y Ciencia.

Hasta 1985, el IRANOR fue el único organismo multisectorial de normalización; el mismo se encargaba de la publicación de las normas UNE y de la representación española en los foros internacionales. Por consiguiente, hasta bien entrada la década de los ochenta la normalización se desarrolla como una función administrativa y con la única aportación de fondos públicos.

Ahora bien, la incorporación de Espańa a la Comunidad Europea aceleró la introducción de importantes cambios en el panorama normalizador. Así, con la aprobación del RD 1614/1985, por el que se ordenaban las actividades de normalización y certificación, se inicia el progresivo desgaje de la función normalizadora desde estructuras administrativas hacia niveles privados. 
Sin embargo, esa cesión de la función normalizadora hacia la iniciativa privada no significó un abandono absoluto de la materia por los poderes públicos. En primer lugar, las funciones en materia de normalización pasaron, de manera más coherente, al Ministerio de Industria y Energía (MINER), al que según el RD 1614/1985 correspondía designar los organismos privados de normalización. Y en segundo lugar, el establecimiento de los organismos privados de normalización quedaba supeditado a un reconocimiento oficial que debía garantizar el cumplimiento de los requisitos fijados de manera reglamentaria.

Esa "privatización" fue llevada a cabo mediante normas reglamentarias, lo cual ofrecía una dudosa cobertura de legalidad al tema de la normalización, lo que hizo necesario que el legislador estableciera un marco general donde se encontrasen los rasgos característicos del sistema de normalización. Esto solo fue cumplido de manera parcial, con la promulgación en 1992 de la Ley de Industria.

Un caso de aplicación práctica de lo establecido para la Unión Europea y para la seguridad y la calidad, se verifica en España.

En efecto, hace más de cincuenta años Villar Palasí sostuvo que “(...) estamos viviendo en nuestros días la superación y arrumbamiento definitivos de viejos sistemas y viejos moldes y el surgimiento y cristalización de nuevas formas y concepciones políticas. El Estado controlador y regulador de la existencia social e individual, pero que abandonaba la total actuación económica a la privata vis, pertenece al pasado. El Estado moderno acompaña al súbdito permanentemente, no solo a través de las clásicas funciones públicas, sino también en el plano -tradicionalmente individual- de lo económico. Hoy el Estado no se enfrenta a la realidad social considerándola como un orden preformado, sino que centra precisamente su máximo de actuación en la conformación de ese orden"39. Estas palabras, parece que siguen teniendo sentido en nuestros días.

Aunque el "péndulo" hoy oscila hacia la acción predominantemente privada, y el Estado ya no es un importante actor económico o empresario directo -lo que de acuerdo a los resultados históricos y los que aun aparecen en los noticieros, redundaron en fracasos estrepitosos- sino que actúa como regulador; por ello la actividad que protege los intereses públicos y/o colectivos en el campo de la industria no se encuentra abolida.

Como se indicó, para el caso específico de Espańa, lo antes dicho se materializa a través de la explicación que se dará sobre la configuración de la seguridad y calidad dentro del marco de la normalización.

En efecto, como se señaló, aquello se materializa en la existencia de un cuerpo normativo básico y atingente a esta materia. Este consiste en la 
Ley de Industria (LI), de $1992^{40}$ el que es complementado por el Reglamento para la Calidad y la Seguridad Industrial (RICSI) de $1995^{41}$. Esta ley dispone en su artículo $1^{\circ}$ que "tiene por objeto establecer las bases de ordenación del sector industrial". Por tanto, tiene un carácter básico en las materias hasta ahora vistas en términos teóricos, pues a través de ella se establecen las potestades atingentes a las administraciones públicas las que intervendrán, utilizarán o participarán de la normalización.

\section{(2.2.2) La distinción entre seguridad y calidad industrial}

La actividad revisada hasta ahora, se concreta especialmente en dos cuestiones centrales: la seguridad y la calidad industrial las que enseguida se pasarán a analizar.

Ello se explica en la medida que, reconociendo sus diferencias, se trata de tareas que resultan inescindibles de cualquier actividad industrial; y, además, pese a tratarse de actividades hoy estrictamente privadas, ofrecen una relevancia para el interés público que justifica su sometimiento -siquiera parcial- al Derecho y en particular al Derecho Administrativo, a través de medidas de control y, en su caso, a través del otorgamiento de subvenciones ${ }^{42}$.

La primera de estas cuestiones, la SEGURIDAD INDUSTRIAL, es considerada núcleo fundamental de la materia de industria, en donde se incluyen las actividades destinadas a la ordenación de los sectores industriales y más precisamente las actividades relacionadas con la seguridad de instalaciones y establecimientos, procesos industriales y productos ${ }^{43}$. Precisamente porque comprende esas actividades, las mismas constituyen título justificativo de intervención administrativa en miras de su finalidad de salvaguarda de la salud e integridad física de las personas, lo que exige necesariamente una actividad de vigilancia sobre dicha actividad y sus resultados; y dicha actividad de vigilancia o control puede ser ejercida directamente por la administración pública competente en virtud de su potestad de policía administrativa, o -más modernamente- controlar por los procedimientos de certificación de productos y procesos industriales con carácter previo a su instalación o puesta a la venta en el mercado, última circunstancia que es prevista en normas técnicas y en certificaciones realizadas por organismos privados previamente acreditados.

La segunda de estas cuestiones, la CALIDAD INDUSTRIAL, si bien es bastante escuetamente tratada, no por ello dejan de establecerse sus objetivos.

Ley 21/1992, de 16 de julio, de Industria.

Real Decreto 2.200 de 1995 publicado en el BOE el 6 de febrero de 1996, y modificado por RD 411 de 1997 publicado en el BOE el 26 de abril de 1997.

TARRÉS (2003a) 385.

STC de Espańa, rol № 243/1994, fundamento $2^{\circ}$. 
En la misma LI, se reconoce la creciente importancia de las disposiciones referentes a normalización, homologación y certificación, desarrolladas por entidades colaboradoras o por laboratorios estrictamente privados. Con ello, ha institucionalizado el ámbito de la calidad, lo que supone un reconocimiento jurídico-público de un conjunto de agentes que no toman como base de su actuación lo previsto en los reglamentos de seguridad dictados por la Administración, sino lo que se contiene en normas técnicas elaboradas por organismos nacionales e internacionales de normalización ${ }^{44}$.

A su vez, estas normas técnicas referidas a productos o procesos de producción, resultan para el fabricante, de aplicación simplemente voluntaria.

\section{(2.2.3) Las entidades relativas a la calidad industrial}

En la LI aparecen como objetivos de la calidad industrial los siguientes: el fomento de los organismos de normalización a nivel nacional; la coordinación y participación de todos los sectores e intereses de la actividad económica y social en la normalización; la colaboración y coordinación de las actividades de normalización con las actuaciones que se desarrollen sobre la materia en el ámbito comunitario, favoreciendo la participación en organismos supranacionales; la existencia de entidades de acreditación, certificación, inspección y ensayo con demostrada capacidad técnica para que puedan ser reconocidas a nivel internacional; la promoción de la implementación y mejora de los sistemas de gestión de calidad de las empresas; y la adquisición por parte de las Administraciones Públicas de productos normalizados.

Para la obtención de dichos cometidos, se han desarrollado tres tipos de entidades: entidades de certificación; laboratorios de ensayo y calibración; y entidades auditoras y de inspección ${ }^{45}$. Las mismas se revisan brevemente a continuación.

(a) Entidades de certificación

Son entidades públicas o privadas cuyo cometido es certificar voluntariamente que una determinada empresa, producto, servicio o persona resulta conforme con los requisitos definidos en las normas o especificaciones técnicas.

Las entidades de certificación deberán ser acreditadas por entidades de acreditación y garantizar su imparcialidad y solvencia técnica. Por 
ejemplo, se prohíbe que estas entidades certifiquen empresas y productos cuando hayan participado anteriormente en actividades de asesoría o consultoría de las mismas empresas o productos.

(b) Laboratorios de ensayo

Son entidades públicas o privadas que se constituyen con la finalidad de llevar a cabo la comprobación solicitada con carácter voluntario, de que los productos cumplen con las normas o especificaciones técnicas que les sean de aplicación.

Rigen para ellos los mismos requisitos de independencia y profesionalidad técnica antedichos.

(c) Entidades auditoras y de inspección

Igualmente, se trata de entes públicos o privados, encargados de determinar si los resultados relativos a la calidad satisfacen los requisitos establecidos; y de controlar que el cumplimiento de dichos requisitos se produce de manera efectiva y duradera.

(d) Laboratorios de calibración industrial

Son los que determinan la trazabilidad y uniformidad de los resultados de medida. Estas entidades, al igual que en todos los demás casos, deben ser acreditados ante las entidades pertinentes, y desarrollan sus actividades en un régimen de voluntariedad.

Pese a las diferencias evidentes entre unas y otras, les une un tratamiento conjunto derivados de sus notas comunes que consisten en las siguientes:

- Pueden ser entidades públicas o privadas;

- Su actividad es solicitada voluntariamente por una empresa;

- Todas esas entidades siguen los criterios establecidos en normas técnicas nacionales e internacionales;

- Para que actúen, se requiere una habilitación previa por parte del organismo acreditador;

- Se establece un régimen de incompatibilidades, entre los distintos procesos considerados; $y$

- Todas estas entidades tiene un deber genérico de información y asistencia técnica para con las administraciones públicas que lo requieran ${ }^{46}$. 


\section{(2.2.4) El caso de la Asociación Espańola de Normalización y Certifi- cación (AENOR) ${ }^{47}$}

En ese descrito marco normativo, el MINER designó, por Orden de 26 de febrero de 1986, a la Asociación Española de Normalización y Certificación (AENOR) como entidad reconocida para desarrollar tareas de normalización y certificación.

Desde entonces AENOR ha venido realizando, en la práctica de forma exclusiva, las actividades relacionadas con la elaboración de normas técnicas. La AENOR es una asociación privada, sin ánimo de lucro, constituida conforme a lo dispuesto en la Ley de asociaciones 191/1964, de 24 de diciembre. Sus estatutos no prevén la existencia de un control público.

Sin embargo, existen tres elementos que permiten constatar una influencia de la Administración en el funcionamiento interno de la asociación. En primer lugar, la misma creación de AENOR se debe a una voluntad del MINER, cuyo impulso fue decisivo para la creación del organismo español de normalización. El segundo argumento atiende a la presencia de representantes de las administraciones públicas en los órganos de gobierno de AENOR. Esta representación está fijada actualmente en el RICSI. Finalmente, y de manera ya más rotunda, existe un reconocimiento oficial del cumplimiento por parte de AENOR de las condiciones y requisitos de organización y funcionamiento que, con carácter general, se exigen a los organismos de normalización. De igual forma se dispone un control administrativo sobre su actuación que garantiza el cumplimiento de las obligaciones reglamentariamente exigidas.

Por su parte, los estatutos de AENOR prevén como fines más destacados de la asociación los siguientes:

- Desarrollar la normalización espańola, coordinándola con la llevada a cabo en ámbitos europeos e internacionales.

- Fomentar y desarrollar las diversas modalidades de certificación de productos, servicios, personas, sistemas, disponiendo de sus propios métodos y marcas de conformidad con normas.

- Colaborar con las administraciones públicas para alcanzar la mayor implantación y utilización de las actividades de normalización y certificación.

- Promover la participación espańola en las organizaciones internacionales y regionales de normalización y certificación, desempeñando en las mismas la representación.

TARRÉS (2000) 147-150. 
Como puede verse, AENOR desarrolla también funciones de certificación. Es decir, realiza también, junto a otras entidades, la actividad que permite establecer la conformidad de una determinada empresa, producto, proceso o servicio con los requisitos definidos en normas técnicas. Este es, seguramente, uno de los aspectos más relevantes que diferencia a AENOR de sus homólogos europeos y que ha sido objeto de controversia en la medida que el ejercicio de funciones de certificación por parte de dicha entidad podría dar lugar a prácticas restrictivas de la competencia. Efectivamente, la posición de AENOR como organismo de normalización y, además, entidad de certificación puede llevar a una eventual colisión de intereses.

Las previsiones mínimas que la Ley de industria establece respecto a la normalización son desarrolladas por el RICSI ${ }^{48}$. Esta norma reglamentaria deroga el anterior RD 1614/1985 y fija un nuevo y más amplio régimen jurídico para la normalización.

De la nueva regulación cabe destacar tres notas principales:

- La competencia para el reconocimiento de una determinada entidad como organismo de normalización ya no se atribuye específicamente al Ministerio de Industria, sino genéricamente a la Administración pública competente en materia de calidad y de seguridad industrial, es decir, a las comunidades autónomas. Ese reconocimiento por parte de la "Administración pública competente" exige además el previo informe positivo del Consejo de Coordinación de la Seguridad Industrial. Una vez reconocido, el organismo de normalización deberá inscribirse en el Registro de establecimientos industriales.

- Sin embargo, el reconocimiento de una pluralidad de administraciones potencialmente competentes para designar organismos de normalización no ha significado por el momento ni la desaparición de AENOR, ni la aparición de otras entidades. Efectivamente, la disposición adicional primera del RICSI ha seguido reconociendo a AENOR como organismo de normalización, con la única obligación de adaptar sus estatutos a los requisitos previstos en el RICSI.

- Pese al interés público que tiene la normalización, la creación de normas técnicas corresponde exclusivamente a entidades privadas. Esto permite considerar que la normalización es una actividad privada en un sentido material.

Una vez designado por la Administración competente, el organismo de normalización deberá actuar con imparcialidad, independencia e integridad y llevar a cabo sus funciones con solvencia técnica y financiera.

48 RD 2200/1995 que contiene el "Reglamento para la calidad y seguridad industrial", publicado en el BOE el 6 de febrero de 1996. 
Como se ha afirmado, desde su creación AENOR ha venido realizando, en la práctica de forma exclusiva, las actividades relacionadas con la elaboración de normas técnicas.

En todo caso, junto a ella, existe otro organismo - esta vez ligado directamente a la Administración Pública- que complementa sus tareas. Es el caso de la Entidad Nacional de Acreditación (ENAC), como organismo designado por la Administración para establecer y mantener el sistema de acreditación a nivel nacional, de acuerdo a normas internacionales, siguiendo en todo momento las políticas y recomendaciones establecidas por la Unión Europea. La ENAC es una organización declarada de utilidad pública, independiente y sin ánimo de lucro, auspiciada y tutelada por la Administración, cuya misión es evaluar la competencia técnica de los organismos de evaluación de la conformidad -Laboratorios, Entidades de Inspección, de Certificación, Verificadores- para generar así confianza en sus actividades a la Administración, al mercado y a la sociedad en general.

De esta forma se consigue que los servicios estén reconocidos y aceptados nacional e internacionalmente, contribuyendo así a una mayor protección de las personas y del medio ambiente y al aumento de la competitividad de los productos y servicios espańoles ${ }^{49}$. Producto de lo anterior, es que -dado este reconocimiento- se ha producido igualmente una progresiva vinculación de las normas técnicas con el ordenamiento jurídico a través de distintos medios ${ }^{50}$.

\section{(2.3) LA ACREDITACIÓN DE LA SEGURIDAD Y CALIDAD INDUSTRIAL. EL CASO DE MÉXICO}

Para el caso de México, es posible adelantar desde ya que el sistema general funciona más o menos de manera similar a los ya revisados. Adicionalmente se destaca que, en relación a esta investigación, existe un ejemplo específico a sistemas y equipos de riego, mismos aspectos que se pasan a explicar.

\section{(2.3.1) El Instituto Mexicano de Normalización y Certificación A.C. $(\text { IMNC) })^{51}$}

Para el caso mexicano, existe el IMNC constituido como una asociación civil sin fines de lucro que tiene como objetivo social normalizar, con

\footnotetext{
49 Antecedentes de la Entidad Nacional de Acreditación (ENAC) disponibles en: http://www.enac.es/web/enac/definicion [22 de diciembre de 2007]

50 Esteve (1999) 173-177.

51 Instituto Mexicano de Normalización y Certificación A.C. IMNC (s/d) http://www. imnc.org.mx/ [11 de marzo de 2008]
} 
el reconocimiento del gobierno mexicano a través de la Dirección General de Normas de la Secretaría de Economía.

En el campo de normalización el IMNC cubre diversos campos a través del trabajo voluntario de organizaciones y profesionales que participan en comités técnicos de normalización nacional, en la elaboración de normas técnicas nacionales e internacionales.

El Comité Técnico de Normalización de Sistemas de Gestión de la Calidad y Evaluación de la Conformidad -comité de normalización que forma parte del IMNC-, es sin duda uno de los pilares debido a las normas mexicanas que este elabora, y que tienen un impacto horizontal en todos los sectores del país. Este comité elabora las normas mexicanas del campo de los sistemas de gestión de calidad equivalentes a las normas elaboradas por el comité técnico de ISO, un ejemplo del trabajo en este rubro es la norma Mexicana NMX.

Dicho comité técnico de normalización, tiene como objetivo dar a conocer la estructura, contenido y la forma de aplicar en los diferentes niveles y modalidades educativos.

\section{(2.3.2) El ejemplo del Comité Técnico de Normalización Nacional de Sistemas y Equipos de Riego (COTENNSER) ${ }^{52}$}

México cuenta con una inmensa superficie de superficie arable de la cual aproximadamente 6,1 millones de hectáreas cuenta con infraestructura de riego (que representan el $40,6 \%$ de su superficie arable).

A fin de irrigar esa superficie se utilizan diversos sistemas de aplicación, de los cuales sobresale el riego por gravedad, con una cobertura de más del $90 \%$, siendo el restante ocupado por sistemas de riego presurizado. Entre estos predomina el riego con tubería con compuertas (aproximadamente el 50\%), les siguen los sistemas de aspersión y, en menor proporción, los sistemas de microaspersión y goteo, principalmente. Todo lo anterior refleja la importancia del enorme potencial que existe en dicho país para la modernización de una infraestructura orientada a elevar la eficiencia de aplicación del agua.

Frente a ello surge el reto de preparar un soporte normativo que permita asegurar los requisitos técnicos, funcionales y legales, de los equipos y materiales utilizados para mejorar o reemplazar la infraestructura existente; disponer de los instrumentos adecuados que permitan asegurar la calidad del diseño y del servicio, de las empresas proveedoras de los sistemas de riego que han de ser instalados. 
Para ello, desde 1992, el Instituto Mexicano de Tecnología del Agua (IMTA $)^{53}$ ha tenido un papel protagónico en la función de normalización nacional en apoyo al sector hidráulico, con su participación en la elaboración de propuestas de anteproyectos de normas oficiales mexicanas (NOM) y normas mexicanas (NMX), así como en la revisión, votación y planteamiento de propuestas de normas internacionales, sobre los temas relacionados con el sector, muy particularmente en tuberías, materiales, métodos sobre medición de flujo, diseño de bancos de prueba y equipos de riego agrícola.

Así, vistos los resultados y el interés del IMTA por el aseguramiento de la calidad en los sistemas de irrigación, el 11 de febrero de 1997, la Dirección General de Normas (DGN), autorizó la formación y coordinación del Grupo Mixto de Normalización, Equipos y Sistemas de Riego (GMN-ESR), bajo el liderazgo del IMTA, el cual inició sus trabajos de normalización el 6 de junio de ese año.

En 1998, en consideración a la labor desempeñada por el Grupo Mixto de Normalización y en concordancia con las reformas a la Ley Federal sobre Metrología y Normalización, este se convirtió en el COMITÉ TÉCNICO DE NORMALIZACIÓN NACIONAL DE SISTEMAS Y EQUIPOS DE RIEGO (COTENNSER), cuyo objetivo es: "elaborar, modificar, revisar y cancelar normas mexicanas en el área específica de sistemas y equipos de riego". Este comité está conformado por representantes especialistas de todos los sectores de la competencia de sistemas y equipos de riego, mismos que se reúnen bimestralmente para discutir y tomar decisiones sobre las propuestas de anteproyectos y la elaboración de normas mexicanas y sobre otros asuntos relacionados con el tema, como son la difusión y capacitación sobre normalización y certificación, así como posibles acuerdos conducentes al desencadenamiento de las acciones necesarias para la construcción de los laboratorios para las pruebas de los equipos normados o en proceso de normalización.

El COTENNSER está constituido por dependencias de la administración pública federal, cámaras nacionales, fideicomisos, asociaciones de usuarios y de fabricantes e instituciones académicas y de investigación superior.

Como comentario final, se quiere insistir en la idea que, a pesar de tratarse de un sistema voluntario, los fabricantes se acogen a estos sistemas de certificación de la calidad como un argumento más de estrategia comercial y como forma de diferenciación ante sus competidores.

53 El Instituto Mexicano de Tecnología del Agua (IMTA) es un organismo público descentralizado que asume los retos nacionales y regionales asociados con el manejo del agua y se dedica a perfilar nuevos enfoques en materia de investigación y desarrollo tecnológico para proteger el recurso y asignarlo de manera eficiente y equitativa entre los distintos usuarios. 


\section{3) UNA DIFERENCIACIÓN NECESARIA: LA DISTINCIÓN Y VINCULACIÓN ENTRE NORMAS TÉCNICAS Y NORMAS JURÍDICAS}

Habiendo realizado toda la revisión anterior, en participar la relativa a los antecedentes contextuales de esta actividad de normalización o estandarización, y a la revisión de regulación jurídica que se ha hecho a su respecto tanto a nivel europeo como de los casos de Derechos nacionales explicados, es necesario trazar algunas diferencias fundamentales antes de adentrarnos en la regulación chilena.

\section{(3.1) La diferencia entre normas técnicas y normas jurídicas}

Desde luego, debe dejarse en claro la muy diferente sustancia y fundamento que presenta el ordenamiento jurídico y el conjunto de normas técnicas, en lo que podría denominarse el ordenamiento técnico.

Así pues, las NORMAS JURIDICAS -consideradas en general y no necesariamente como una ley, pues puede ser Derecho consuetudinario o principios jurídicos concretizados-, han de observarse no porque sean acertadas o justas, sino que fundamentalmente por su procedencia de una determinada instancia, y precedida de un determinado procedimiento. De este modo, las normas jurídicas ganan su legitimación y fuerza vinculante a partir -esencialmente- del procedimiento formal de su elaboración y, además, en la posibilidad que existe para hacer uso de la fuerza socialmente organizada para hacer que se cumplan. Supone un hecho descrito genéricamente en la "regla" como enunciado, al que va unido una consecuencia jurídica circunscrita de modo general también. De esta forma, la consecuencia jurídica enlazada a su supuesto de hecho, constituye la norma jurídica completa ${ }^{54}$.

En cambio, las NORMAS TÉCNICAS no se fundan en procedimientos formales, sino que tratan de obtener su legitimación en los conocimientos y competencia técnica y científicas de quienes las elaboran ${ }^{55}$. Ahora bien, el contenido de estas normas, siempre quedará abierto a dos posibles vías de revisión: el contraste empírico; y la autoridad científica o técnica de quienes las elaboran.

Ambas, contienen proposiciones, habitualmente enunciativas y con pretensiones de validez; pero en el caso de las jurídicas, estas contienen enunciados sobre el Derecho vigente y por tanto, son obligatorias.

Por ello, si a las normas jurídicas es consustancial la idea de fijeza, certeza y seguridad jurídica; a las normas técnicas, en virtud de los cons-

\footnotetext{
54 Larenz, K. (2001). Metodologia de la Ciencia del Derecho. Barcelona: Ariel Derecho, pp. 242-245.

55 Por ello, se justifica claramente la referencia a la auctoritas en relación a las normas técnicas.
} 
tantes cambios y avances en dicha área, la mutabilidad, el progreso, la innovación y la corrección a partir de los resultados de la experiencia aplicada son sus elementos característicos.

\section{(3.2) LA RELACIÓN DE LAS NORMAS TÉCNICAS CON EL ORDENAMIEN- TO JURÍDICO}

\section{(3.2.1) La relación en términos generales}

En virtud de lo ya dicho, a lo menos en este ámbito es posible detectar una recomposición del ordenamiento jurídico, en la medida que se entrega -por acción u omisión como se verá- la regulación de amplios sectores y con una importante relevancia, a una constelación de entidades con una supuesta capacidad técnica, de nivel nacional e internacional ${ }^{56}$.

Aquello ocurre no solo, como fue en los inicios, generando en el ámbito de la normalización un tipo de "normas de producto" relativas a los productos industriales propiamente tales, sino que también existen hoy "normas de empresa" relativas a la organización del conjunto de la empresa. Entre estas últimas las más famosas son las normas ISO de la serie 9000 para el campo de la gestión de calidad de la empresa, y las de la serie 14000 en el ámbito de la gestión medioambiental.

Este panorama se complejiza, pero al mismo tiempo explica su actual configuración, cuando se considera la ampliación de sus fines. En efecto, inicialmente su preocupación pasaba por la compatibilidad e intercambiabilidad; para luego velar por la racionalización de la variedad o el aseguramiento de la salubridad y calidad; para hoy, finalmente, abrirse paso las preocupaciones medioambientales y de protección de los consumidores todo ello con una marcada internacionalización de esta clase de disposiciones.

A partir de esta enorme realidad los Estados europeos han tratado de encauzar, racionalizar y, hasta cierto punto, reconocer e integrar la normalización de origen privado.

Como se explicó, ejemplo de ello ocurre en Francia con la Association Française de Normalisation (AFNOR) que fue creada en 1926 como asociación privada, aunque intervenida desde la comisión interministerial de control de la normalización; en Gran Bretańa con la British Standards Institution (BSI) que obtuvo reconocimiento oficial mediante una carta real; y en Alemania se suscribió un convenio entre el ministerio de Economía y el Deutsches Institut für Normung (DIN). Otro tanto ocurre en Espańa, donde el MINER designó a la Asociación Española de Normalización y Certificación (AENOR) como entidad reconocida para desarrollar tareas de normalización y certificación. 
La actividad explicada hasta el momento, que -se ha dicho- ha preterido a la Administración aunque se trata de una actividad materialmente administrativa a lo menos en su faz concreta, ha podido ser resuelta y abordada por el Derecho, teniendo como base la clásica intervención administrativa que concreta actividades sustancialmente público-administrativas, a saber: policía/ordenación (que comprende regulación, inspección y sanción), servicio público, fomento, gestión empresarial y gestión de bienes públicos (por medio de autorizaciones, permisos y/o concesiones).

Sin embargo, aquello, como se ha visto, en el ámbito de la técnica y gestión de riesgos y más recientemente de la calidad, el ordenamiento jurídico en general y la Administración Pública en especial, se han servido siempre de la experiencia técnica del sector privado, entregándoles a ellos el ejercicio de claras funciones públicas. Así por ejemplo, la inspección y control del cumplimiento de normas técnicas que por motivos de seguridad y/o calidad tiene que observar ciertos productos o instalaciones industriales, se apoya o auxilia en laboratorios de ensayos y calibración de empresas o profesionales especializados en la instalación y mantenimiento de aparatos y en entidades privadas de certificación ${ }^{57}$.

\section{(3.2.2) El instrumento de vinculación: las "fórmulas remisoras"}

Ahora bien, como se ha venido sosteniendo en este trabajo, la Administración Pública en especial, se han servido siempre de la experiencia técnica del sector privado, entregándoles a ellos el ejercicio de claras funciones públicas. Pues bien, uno de los medios a través de los cuales se manifiesta esto, es a través de la vinculación concreta de las normas técnicas emitidas por la ISO o el INN con el ordenamiento jurídico en el uso que se hace de ellas a través de la remisión normativa.

En este mismo orden de ideas, atendida la naturaleza y las formas revisadas, es posible distinguir tres clases de reenvíos, a saber:

\section{(a) Remisión nominada o estática}

Se da cuando una norma se remite a lo que explícitamente establece una norma técnica, que se identifica de manera precisa con sus datos externos (su título y número, año de aprobación o edición, etc.). Si bien, en principio, esta fórmula no plantea objeciones desde consideraciones de estricta técnica jurídica, con ella se cierra la entrada a la corriente dinámica de la evolución y adaptación tecnológica, con lo cual su obsolescencia ante el desarrollo tecnológico es previsible. 
De todos modos, para el caso en que así se produzca la remisión, la norma técnica no solo debe ser publicada, sino que, además, es indispensable la efectiva divulgación de ella por cualquier medio adecuado.

Aquello, sin embargo, genera un problema pues las normas técnicas elaboradas por los organismos privados de normalización estarían protegidas por los derechos de propiedad intelectual, circunstancia que limita la divulgación indiscrimidada de esta clase de normas, pero no la impide pues se puede acceder a ella a través de la compra de las mismas por los interesados ${ }^{58}$.

(b) Remisión innominada o dinámica

En este caso, la norma remitente no precisa como destino de la remisión una norma técnica concreta, sino que señala una serie o tipo de normas que irán modificándose sucesivamente. Esta remisión ofrece indudables ventajas al superar la rigidez del sistema de remisión estática y quedar abierta a la posibilidad de aceptar la modificación de las normas técnicas remitidas, sin necesidad de proceder a la actualización de la norma jurídica remitente.

La remisión debiera referirse en consecuencia a la expresión genérica a las normas ISO, NCh u otra. Se plantea, sin embargo, una objeción sustantiva, toda vez que el legislador a través de la utilización de esta fórmula realizaría una delegación fáctica de su competencia normativa a un organismo privado al permitirle alterar el contenido normativo de una norma legal. En este caso estaríamos ante una norma eventualmente inconstitucional.

(c) Remisión indirecta a través de cláusula técnica

En este caso el objeto de la remisión no se expresa mediante la norma técnica en sí misma, sino que a través de una cláusula técnica. Se utiliza así, una norma concretizadora (una normkretisierende gleitende Verweisung del Derecho alemán) en que la norma jurídica remitente establece unos requisitos generales no detallados que encuentran su concreción en normas técnicas a través de cláusulas generales o conceptos jurídicos indeterminados, lo que no registra objeción alguna.

Esta es la fórmula que se estima por la doctrina como la más idónea, pues permitiría combinar adecuadamente los dos componentes anteriores: por un lado se establece una conexión con el ordenamiento jurídico; y por otro, la mantiene la necesaria flexibilidad para incorporar el progreso tación Administrativa № 265-266, pp. 173-178. 
tecnológico. En este caso, las fórmulas a utilizar por la norma jurídica serían "la mejor tecnología disponible", el "estado de la técnica", "reglas generalmente (re)conocidas", "”estado (progreso, evolución) de la técnica", los "conocimientos científicos en la materia" u otras similares 59 . La función de la norma técnica será la de constituir un elemento de concreción del ordenamiento jurídico allí donde se recurre a esos conceptos jurídicos indeterminados. Sin embargo, es cierto que puede ser considerada muy amplia, y por tanto difícil de controlar, por lo que la fórmula de remisión innominada o dinámica puede cumplir dicho cometido.

A través de esta fórmula remisiva se puede cumplir con la exigencia de juridicidad general de la ley y de especificación de la exigencia del reglamento.

\section{4) LOS PROCESOS NORMOGÉNICOS DE CREACIÓN DE NORMAS TÉCNI- CAS EN CHILE Y SUS EFECTOS JURÍDICOS}

Hecha toda la revisión anterior, es claramente afirmable que lo visto hasta ahora constituye un supuesto prototípico de ejercicio por particulares de funciones públicas, en donde sujetos ajenos al "aparato administrativo" desarrollan por atribución funciones normativas y ejecutivas de innegable naturaleza pública en atención a sus efectos; funciones que ejercen en nombre propio y con plena autonomía funcional, sin imputar el resultado de la misma ni la responsabilidad derivada de ella a la Administración Pública ${ }^{60}$. Ello no obsta a la existencia de técnicas de control y tutela administrativa que con distinto alcance y contenido, se proyectan sobre la ordenación y el resultado de su actividad.

Para esto es precisamente que se pasará a revisar a continuación los procesos normogénicos de creación de estas normas técnicas, algunos ejemplos de normas técnicas aplicados en nuestro país y el deficiente sistema de control público de los sistemas privados de inspección, certificación y acreditación técnica.

\section{(4.1) PRocesos NORMOGÉNICOS DE CREACIÓN DE NORMAS TÉCNICAS EN NUESTRO PAÍS}

En Chile, el estudio y la elaboración de estas normas fue la actividad principal de Inditecnor y luego, desde su creación, del $\mathrm{INN}^{61}$.

\footnotetext{
59 TARRÉS (2003b) 181-182.

60 Carrillo (2009) 104.

61 Aunque la preocupación por la calidad y la normalización de los procesos productivos tiene una historia que se remonta a comienzos del siglo XX, el tema comenzó a ser una seria preocupación internacional solo después de la Segunda Guerra Mundial. Por esos ańos,
} 
A partir de la década de 1990, especialmente desde 1996, ha habido un impulso a esta área tanto desde el punto de vista profesional como de los procesos. Actualmente, la División de Normas del INN está validada en el mercado, tanto público como privado, y sus expertos estudian y redactan las normas con la experiencia de poseer una larga trayectoria en el INN, único organismo nacional dedicado específicamente al tema. La gran misión en esta área es la de elaborar y difundir las Normas Chilenas (NCh), además de ayudar a detectar necesidades de nuevas normas.

Como parte del crecimiento y globalización de los mercados, las empresas deben desarrollar sus procesos productivos de acuerdo a normas reconocidas nacional e internacionalmente, es decir, a documentos de conocimiento y uso públicos, establecidos por consenso y aprobados por un organismo reconocido.

Asimismo, sugieren - para usos comunes y repetidos- reglas, criterios o características para las actividades o sus resultados y procuran la obtención de un nivel óptimo de ordenamiento en un contexto determinado. De este modo ayudan a mejorar la calidad, la seguridad y la competitividad industrial, ya que especifican la calidad de un producto o servicio, al definir el conjunto de propiedades o características requeridas para cumplir su función de uso en forma satisfactoria.

Coherente con criterios internacionales, establecidos en los Acuerdos de la Organización Mundial del Comercio (OMC), el resto de las áreas, reguladas por el mercado, debieran regirse por las normas voluntarias establecidas por consenso y cuya ausencia de cumplimiento solo puede ser sancionada por el propio mercado.

Chile vivía un acelerado proceso de industrialización, profundizado en el gobierno de Pedro Aguirre Cerda con la instauración de la CORFO, en 1939. Cinco ańos después fue creado el Instituto de Investigaciones Tecnológicas y Normalización (INDITECNOR), precedente del actual INN. Así el el INN fue creado por CORFO según D.S. № 678, de 5 de julio de 1973, con énfasis en sus funciones de normalización, acreditación y metrología, de modo de ofrecer a las empresas instrumentos para impulsar el control de calidad. Aunque el Decreto Supremo 678, que dio vida y personalidad jurídica al INN, tiene fecha del 5 de julio de 1973, el Instituto comenzó a funcionar el 1 de dicho mes y año con todo el personal de INDITECNOR.

Entre 1973 y los primeros años de la década de 1990, las actividades desarrolladas por el INN fueron la normalización, la venta de normas, la capacitación en control de calidad y, a partir de 1978, la calificación de entidades de certificación. Hasta 1976 realizó actividades de inspección y certificación de productos, en especial para el Ministerio de Vivienda. Entre 1976 y 1978 fueron iniciados los estudios tendientes a formar un sistema de certificación, creándose el Sistema Nacional de Calificación de Entidades de Certificación, que permaneció activo hasta 1996. Aunque las labores de capacitación siempre fueron importantes para el Instituto, recién a partir de 1981 se consolidó e hizo permanente a mediados de la década siguiente. En julio de 1986, el Decreto No 533 del Ministerio de Justicia modificó los estatutos, lo que significó que los miembros del Consejo dejaran de realizar sus funciones ad honorem y que fuera incorporada entre sus actividades la administración de un Sistema Nacional de Certificación de Conformidad. Por otro lado, el INN obtuvo ese mismo año la calidad de instituto de investigación del Estado. 
La existencia de las normas conlleva diversos beneficios que pueden resumirse en la reducción de las barreras técnicas al comercio; el optimizar el uso de los recursos productivos en las empresas; la mayor información del usuario para escoger los productos más aptos y seguros; la transferencia en el uso de nuevas tecnologías; el apoyo a la autoridad reglamentaria que utiliza las normas como un complemento de la reglamentación; y la disponibilidad de un lenguaje común, que permite la comunicación y el entendimiento entre distintos sectores.

En el estudio y aprobación de una Norma Chilena (NCh), el INN contempla la participación de productores, importadores y comercializadores; consumidores y/o usuarios; organismos de Gobierno, universidades, laboratorios y organismos de investigación en ciencia y técnica ${ }^{62}$.

La detección de la necesidad de una norma -por el INN o por petición desde el sector público o privado- da inicio al proceso. Luego se busca el financiamiento necesario, es constituido el Comité Técnico y elaborado el anteproyecto de norma. Si existen normas internacionales, se adaptan para cumplir los protocolos de la Organización Mundial de Comercio; de no haberlas, son consultadas normas regionales, de otros países y/o de empresas del rubro.

Una vez redactado, el proyecto se somete a consulta pública. En esta consulta deben participar las autoridades competentes, los productores, los representantes del mundo de la ciencia y la tecnología, y los consumidores o usuarios. La participación de este último sector representa una dificultad mundial, debido a que en la mayoría de los países no están suficientemente organizados o lo hacen en torno a materias legales y no técnicas.

Las observaciones de la consulta pública son llevadas nuevamente al Comité Técnico, que resuelve su pertinencia, llega a un texto consensuado y propone al Consejo del INN la aprobación de la norma.

Una vez realizada esta faz, la Norma Chilena es remitida al ministerio respectivo para que este la oficialice.

\section{(4.2) EJEMPLOS DE FÓRMULAS REMISORAS A NORMAS TÉCNICAS, YA USADAS EN NUESTRO PAÍS}

En el caso chileno, existen ejemplos de remisiones ya usadas en reglamentos y ordenanzas. Un ejemplo es el RegLamento dE TRANSPOrTe DE CARGaS PELIGRosas POR CALles y CAMinos ${ }^{63}$, que en su artículo $2^{\circ}$ señala que "Se consideran sustancias peligrosas aquellas que se definen en

62 Instituto Nacional de Normalización (2004). Calidad un proyecto pais. Santiago: autoedición, pp. 8-14. Disponible en http://www3.inn.cl/pdfs/docinstitucionales/memoria2004.pdf [14 de noviembre de 2007].

63 Decreto MTT No 298 de 11 de febrero de 1995. 
las Normas Chilenas Oficial NCh 382.Of89 y NCh 2120/1 al 9.Of89". La misma técnica se utiliza en el artículo $4^{\circ}$ donde dispone: "Durante las operaciones de carga, transporte, descarga, transbordo y limpieza, los vehículos deberán portar los rótulos a que se refiere la Norma Chilena Oficial NCh 2190. Of93 (...)". También hay referencias similares en el artículo 7,30 y 34 .

Otros ejemplos, en el mismo sentido anterior, se presentan en la $\mathrm{O}_{R-}$ denanza General de Urbanismo y Construcciones que en sus disposiciones reglamentarias se refiere a normas técnicas en aproximadamente ochenta oportunidades.

Abunda en antecedentes el hecho que con fecha 28 de enero de 2003 fue publicado el Decreto MOP No 50, el cual fija el RegLAMENTO DE INSTALACIONES DOMICILIARIAS DE AGUA POTABLE Y ALCANTARILLADO (RIDDA), que trata acerca de los proyectos, la construcción y la puesta en servicio de las instalaciones domiciliarias de agua potable y alcantarillado y establece, además, las normas técnicas para este tipo de instalaciones y que rigen para todo el territorio nacional.

Dentro de toda la reglamentación existe la obligatoriedad de certificación de todos los materiales, artefactos, componentes, equipos y sistemas que se ocupan en estas instalaciones, lo que deberán además ser autorizados por la SISS. La certificación deberá ser bajo los procedimientos de calidad dispuestos por la SISS y ser otorgada por organismos acreditados en el Sistema Nacional de Acreditación del INN. Para la certificación, se deberá cumplir con las Normas Chilenas Oficiales vigentes al respecto o a la falta de ellas, con las especificaciones Técnicas que fije la SISS. La SISS para este efecto mantendrá un listado autorizado de materiales y componentes que se puedan usar en las instalaciones sanitarias.

En los casos de no existir Normas Chilenas para un determinado material, componente, artefacto, equipo o sistema, la SISS podrá autorizar en forma provisoria aquellos que cumplan los requisitos estipulados en normas extranjeras debidamente homologadas por el INN.

\section{(4.3) PROBLEMAS DERIVAdOS DE LA REMISIÓN}

\section{(4.3.1) Escasa y casuista regulación jurídica}

En nuestro país no existe una regulación legal explícita y completa sobre la materia.

Quizá haya un antecedente de esto en materia de seguridad industrial, por medio de la Ley No 16.744 sobre Seguro Social contra RIESGOS DE ACCIDENTES DEL TRABAJO Y ENFERMEDADES PROFESIONALES, $Y$ en la Ley de Urbanismo y Construcciones y su Ordenanza, en la medida que entregan a organismos de formación compleja, e integrados por entes públicos y privados las cuestiones tan delicadas como las que tratan. 
Pero lo cierto es que en otros ámbitos -como la calidad industrial-, se echa en falta en nuestro país una regulación completa que ordene el área, a nivel legal.

Aquello no corresponde en absoluto a la importancia que esta materia ha cobrado en el terreno de la producción y la gestión empresarial en el contexto de mercados abiertos, como se ha explicitado anteriormente. Según se puede observar, la acreditación constituye la conditio sine qua non para la inclusión de una entidad en el espacio de la calidad o la seguridad industrial.

Expresiones como "calidad industrial", "gestión integrada de calidad" o "calidad total" son, sin duda, conceptos que han revolucionados las disciplinas que se encargan de la administración empresarial ${ }^{64}$.

Desde el punto de vista de técnica jurídica, seguridad industrial por un lado y la calidad industrial por el otro, se asientan sobre la base de tres conceptos claves y complementarios: la normalización y la certificación, con una acreditación de por medio como se ha puesto de relevancia anteriormente.

En primer lugar, NORMALIZAR es establecer a través de una entidad privada de carácter asociativo y plurirrepresentativo, documentos convencionales de aplicación voluntaria (estándares o "normas técnicas") que tiene como objetivo la tipificación, unificación y especificación de los sistemas, procesos, equipos y productos industriales a fin de racionalizar el mercado productivo ${ }^{65}$. Luego, la ACREDITACIón es el procedimiento por el cual la autoridad reconoce formalmente que un organismo es competente para efectuar tareas específicas; o, más modernamente, es definida como la atestación de tercera persona relativa a un órgano de evaluación de la conformidad, que constituye la demostración formal de su competencia para llevar a cabo tareas específicas. En fin, la CERTIFICACIón corresponde a un concreto procedimiento de comprobación de la sujeción de dichos sistemas, procesos, equipos y productos a los requisitos y especificaciones técnicas establecidos para estos en "normas técnicas" que los contemplan, de forma que, si estos requisitos y especificaciones están recogidos en disposiciones reglamentarias de seguridad, el procedimiento de comprobación de su cumplimiento será un procedimiento de alcance público y efectos autorizatorios. Por el contrario, si los procedimientos aplicables son referenciales de calidad establecidos en normas técnicas voluntarias, la certificación es un procedimiento totalmente privado que es llevado a cabo por una entidad independiente cuya competencia técnica ha sido previamente acreditada $^{66}$. 
Así, el juego de estos tres elementos construye un sistema autorizatorio o certificatorio que debe responder a criterios internacionalmente aceptados al servicio de fines públicos de diverso alcance.

Esto es muy relevante, sobre todo por el hecho cierto que el principal factor de crecimiento económico de las sociedades industriales pasa por la innovación en los procesos productivos. Por ello, dada la incidencia directa en el crecimiento económico de los países, al Estado le corresponde adoptar una actitud positiva de intervención o regulación sobre aquellas actividades vinculadas con el desarrollo del país ${ }^{67}$. Entre aquellas delicadas cuestiones con incidencia en este punto, se encuentra precisamente la de la calidad industrial, la que no puede ser dejada al manejo exclusivo de los agentes del mercado, dada su importancia estratégica vital para la homogeneización y la competitividad del mercado y la industria nacional, y como vía idónea para satisfacer intereses públicos ligados al consumo y a los derechos e intereses de los consumidores o usuarios.

Y, producto de la especialización o profesionalidad otorgada por la técnica, o en virtud de la evolución histórica, existen entes dotados de un conocimiento específico -autoridad en sentido clásico-, al que suman la potestad -o sea, ese poder concreto otorgado por el ordenamiento jurídico-, a que se ha hecho referencia. Ya no se trata de personas u órganos integrados a la Administración burocrática, sino que se trata de personas o entidades jurídicas que tienen este carácter en razón de su especialización técnica o en virtud de una decisión política en tal sentido ostentando la condición de autoridad, pero de modo diverso del anterior, esto es, como AUTORIDAD FUNCIONAL; la que es una especie de aquella genérica basada no precisamente en la posesión de un cargo, sino que se basa en un conocimiento especializado, en conocimientos técnicos, en un reconocimiento social institucional y en último término en una atribución legal de tal carácter ${ }^{68}$. Pareciera, en consecuencia, que este tipo de autoridad se vincula con el concepto original de auctoritas, no dependiendo su cualidad del ejercicio de un determinado cargo dentro de una organización administrativa, ni ostentando tal condición inherente al cargo de que se es titular; sino que es autoridad por ser autor de una decisión, ostentando el saber especializado o las facultades decisorias ${ }^{69}$.

Carrillo (2000) 38.

Canals i Ametller, D. (2003) El ejercicio por particulares de funciones de autoridad. Control, inspección y certificación. Granada: Comares, pp. 214-217.

En efecto AUTORIDAD proviene de auctoritas, que se dice de "aquel a quien se le reconoce la capacidad para ser auctor y desde el punto de vista jurídico-público, aquel que fundamenta una decisión o la perfecciona jurídicamente por su ratificación, pero sin formular necesariamente por sí mismo el contenido de la decisión y sin realizar por sí mismo los actos necesarios para su ejecución, lo que pertenece a la potestas. Por consiguiente tiene autoridad quien por su iniciativa o ratificación legitima, fundamenta y, por tanto, garantiza y acrece los actos de potestad". García Pelayo, M (1983) "Auctoritas". En Él mismo (1991). Obras Completas. Tomo II. Madrid: Centro de Estudios Constitucionales, p. 1864. 
Esta autoridad funcional implica el ejercicio de una POTESTAD/ FUNCIÓN ${ }^{70}$-como no puede ser de otro modo ${ }^{71}$, en la medida que es un poder jurídico concreto, conferido por el ordenamiento jurídico a la organización ejerciente de esta autoridad funcional, que lleva asimismo implícita una obligación de sujeción por parte de los sujetos a ella vinculados ${ }^{72}$.

Dado lo anterior, se prevé para ello la sujeción al Derecho Administrativo de dichas actividades, aunque esté encomendado siquiera parcialmente a entes o entidades u organizaciones sometidas parcialmente al Derecho privado, lo que determina la aplicación del Derecho Administrativo por entes de base privada.

Como se ha seńalado, lo anterior no es un hecho aislado ni excepcional, en tanto dichos entes ejercen funciones o potestades administrativas actúan como administraciones públicas y su régimen jurídico será en esa medida el Derecho Administrativo, dado que es la actuación de autoridad y poder público -aun llevada a cabo por personas privadas-, la que determina su régimen jurídico, siendo lo determinante para la aplicación de dicho Derecho el ejercicio de la autoridad pública o funciones públicas

Por su parte POTESTAD proviene de potestas, que es el poder de mando socialmente reconocido; y que clásicamente estaba asignado al pueblo en Roma en contraposición de la autoridad que tenía el Senado romano, ligada a la posición social e influencia política, en último término a la autoridad o sabiduría socialmente reconocida. Sin embargo, dichos conceptos son luego confundidos a partir del principado de Augusto toda vez que el título de princeps expresa una auctoritas ligada esta vez a la persona -una auctoritas magnificada-, con una significación político-espiritual, confundiéndose de este modo con cualquier poder político superior. Luego, con la aparición del Estado moderno a partir de la configuración que de este se hace desde el siglo XVIII, surge la forma moderna de autoridad, donde esta se le atribuye al Estado confundiéndose con él, dado que potestad y autoridad son los presupuestos básicos sobre los que se estructura esta moderna noción confundidas en su esencia estas dos ideas de potestas y auctoritas. Y esto resulta acertado toda vez que desde una perspectiva jurídica, la superioridad y sabiduría no son suficientes para obedecer lo que en ellas se dispone; así la autoridad necesita de reconocimiento jurídico expresado por el Derecho, lo que la hace al mismo tiempo ser legítima, y en ese sentido está justificada en el Estado de Derecho. García Pelayo (1991) 1887.

$70 \mathrm{Y}$ en puridad estas son genuinas potestades administrativas, entendidas como facultades o poderes genéricos que se atribuyen a las organizaciones públicas en cuanto actúan revestidas de las prerrogativas típicas de poder. Menéndez Rexach, A. (1997). "La aplicación de la Ley 30/1992 a las entidades públicas empresariales". En Vv. AA. Valoración de la Ley $30 / 1992$ tras cinco años de vigencia. Madrid: Cuadernos de Derecho Judicial, p. 24.

71 Como certeramente afirma SuNÉ "toda potestad ha de ser necesariamente 'potestad-función', por cuanto el ejercicio del poder público, como restrictivo de la libertad individual que es por esencia, solo puede legitimarse con su utilización al servicio del interés general". SuŃ́ Luinás, E. (1989). "Sobre el concepto de potestad". En Gómez Ferrer, Rafael (coordinación). Libro homenaje al profesor José Luis Villar Palasí. Madrid: Civitas, p. 1351.

72 A similar conclusión arriba en específico a propósito de la función administrativa de inspección y control. Así sostiene que, las funciones de control, inspección y certificación que son ejercidas por los agentes privados en el sistema de control de riesgos de la técnica, se caracterizan por ser funciones de marcado contenido jurídico, pues se encargan de inspeccionar el cumplimiento de las leyes en las cuales es consustancial la inspección técnica, constituyendo una "inspección plena". Canals (2003) 226-227. 
de autoridad, con independencia de la pertenencia orgánica de la entidad que lo ejerza. Ejemplo evidente de ello está constituido tanto por el INN como por los organismos certificadores privados; pues el primero, a través del instrumento de la normalización y la acreditación, permite que los segundos certifiquen o den conformidad.

No obstante la falta de regulación legal, y la entrega a reglamentos u ordenanzas de las referencias jurídicas vinculadas con normas técnicas en lo relativo a estas áreas tan sensibles -como son la seguridad y la calidad-, hace que la seguridad jurídica y la vinculación a la ley de la actuación de órganos administrativos por último tuteladores de estos preciosos bienes, se tornó claramente feble.

Ni qué decir de una eventual violación a lo dispuesto en los artículos 6 y 7 de la Constitución Política, derivada de la faltar de esa regulación legal.

\section{(4.3.2) Escaso control público}

Tal y como se ha presentado esta situación, en donde además está comprometido claramente el interés público tutelado en principio por aquella organización encargada de velar por todo aquello que no sea legislar o juzgar -la Administración Pública-, se ha remitido en favor de organizaciones privadas sus obligaciones de aseguramiento de seguridad y calidad, bienes jurídicos carísimos a toda la población.

Sin perjuicio de lo anterior, y a lo menos para el INN es aplicable la siguiente clase de controles:

(a) Ley No 10.336, Orgánica de la Contraloría General de la República

Consideradas en el artículo 16 inciso $2^{\circ}$, en cuya virtud quedarán sujetas a la fiscalización de la CGR las empresas, sociedades o entidades públicas o privadas en que el Estado o sus empresas, sociedades o instituciones centralizadas o descentralizadas tengan aportes de capital mayoritario o en igual proporción, o, en las mismas condiciones, representación o participación, para los efectos de cautelar el cumplimiento de los fines de esas empresas, sociedades o entidades, la regularidad de sus operaciones, hacer efectivas las responsabilidades de sus directivos o empleados, y obtener la información o antecedentes necesarios para formular un Balance Nacional.

(b) D.L. No 1.262 sobre administración financiera del Estado, de 1975

En cuya virtud, de acuerdo a lo previsto en el artículo 44, los actos administrativos de los servicios públicos, de las empresas del Estado, de las empresas, sociedades o instituciones en las que el sector público o sus 
empresas tengan un aporte de capital superior al 50\% de su capital social, que de cualquier modo puedan comprometer el crédito público, solo podrán iniciarse previa autorización del Ministerio de Hacienda.

\section{(c) Ley No 20.285 sobre acceso a la información pública}

A esta clase de controles -fundamentalmente de gestión y formales-, se debe sumar necesariamente el control que se propone por medio de la Ley № 20.285 "sobre acceso a la información pública", ello sin perjuicio de lo ya dicho acerca del sistema restringido de publicidad del sistema de normas técnicas que realiza el INN.

Esto, de algún modo, debe repararse.

\section{CONCLUSIONES}

Al finalizar este trabajo es posible arribar al siguiente grupo de conclusiones:

1) La NORMALIZACIÓN es un medio que la técnica ha encontrado para regular algunas cuestiones vinculadas con el cumplimiento de condiciones de dicha naturaleza en la cual hay interés privado y de los poderes públicos, en tanto por su intermedio se accede a un instrumento que permite la defensa medioambiental, la protección de la salud, la seguridad, el derecho de los consumidores, y el fomento de la actividad industrial de calidad. Y esto, en el ámbito internacional se encuentra regulado por la International Organization for Standarization (ISO) y en nuestro país por el Instituto Nacional de Normalización (INN).

2) Estas normas técnicas y los procesos normalizadores, han tenido una concreción en el ámbito normativo -ahora de tipo jurídico- en distintos órdenes. Para ello se revisaron los casos de la Unión Europea, Espańa y más sucintamente los de Alemania y México, todos los que usan fórmulas más o menos similares basados en la distinción entre actividades de normalización, acreditación y certificación, procesos en donde concurren tanto administraciones públicas especializadas como organismos privados.

3) Sin embargo, este proceso no aparece desligado de su proyección y concreción a un nivel jurídico, teniendo vinculación esta clase de normativas técnicas con las propiamente jurídicas. Ello en la medida que, algunas de estas normas técnicas pasan a ser exigibles jurídicamente por diversos medios propios de la juridicidad.

Se utilizan al efecto, fórmulas remisivas en distintos cuerpos normativos de tipo jurídico que, por reenvío, generan una exigibilidad u 
obligatoriedad jurídica de esta clase de normas basadas en parámetros técnicos, fijadas por organismos internacionales con correlación nacional; lo que puede generar diversos problemas.

4) En el caso de Chile se detectan inicialmente dos problemas: una escasa y casuística regulación jurídica, pues solo en algunos cuerpos normativos de tipo jurídico muy específico y en ningún caso de modo general se hace este correlato; y un escaso y tangencial control jurídico de esta clase de actividades.

Ambas cuestiones debieran repararse dada la enorme trascendencia que en cuestiones tan sensibles y cotidianas como la seguridad en la realización de actividades industriales, así como la calidad de las mismas y de sus productos, tiene esta temática.

\section{BIBLIOGRAFÍA}

Álvarez García, V. (1998). "Introducción a los problemas jurídicos de la normalización industrial: normalización industrial y sistema de fuentes". RAP No 147.

Bermejo Vera, J. et al. (2005). Derecho Administrativo. Parte especial. Cizur Menor (Navarra): Civitas.

Canals i Ametller, D. (2003). El ejercicio por particulares de funciones de autoridad. Control, inspección y certificación. Granada: Comares.

Carrillo Donaire, J. A. (2000). El Derecho de la seguridad y de la calidad industrial. Madrid: Marcial Pons.

(2009). "Seguridad y calidad productiva: de la intervención policial a la gestión de riesgos". RAP No 178 .

COMITÉ TÉCNICO DE NORMALIZACION NACIONAL DE SISTEMAS Y EQUIPOS DE RIEGO. COTENNSER (s/d): http://www.imta.gob.mx/enlacesi$\mathrm{mta} /$ cotennser.htm [11 de marzo de 2008]

Darnaculleta i Gardella, M. (2005). Autorregulación y Derecho Público: la autorregulación regulada. Madrid: Marcial Pons, 2005.

De la Riva, I. (2004). Ayudas públicas. Incidencia de la intervención estatal en el funcionamiento del mercado. Buenos Aires: Hammurabi.

Esteve Pardo, J. (1999). Técnica, riesgo y Derecho. Barcelona: Ariel Derecho.

Entidad Nacional de Acreditación (ENAC). Disponible en http:// www.enac.es/web/enac/definicion [22 de diciembre de 2007].

Europa. El portal de la Unión Europea. Estados miembros de la Unión Europea. Disponible en http://europa.eu/abc/european_countries/ index_es.htm [20 de diciembre de 2007]

Fernández García, A. (2005). Participación y colaboración ciudadana en la Administración agraria. Madrid: INAP.

García Pelayo, M (1983). "Auctoritas". En Él mismo (1991). Obras Completas. Tomo II. Madrid: Centro de Estudios Constitucionales. 
Instituto Mexicano de Normalización y Certificación A.C. IMNC (s/d): http://www.imnc.org.mx/ [11 de marzo de 2008]

Instituto Nacional de Normalización (2004). Calidad un proyecto país. Santiago: autoedición. Disponible en http://www3.inn.cl/pdfs/ docinstitucionales/memoria2004.pdf [14 de noviembre de 2007].

"Flujograma de estudio de norma técnica en el INN". Disponible en http://www3.inn.cl/normalizacion/estudio/portada/index. php [20 de diciembre de 2007]

International Organization for Standarization (ISO): "ISO members" http://www.iso.org/iso/about/iso_members/iso_member_body. htm? member_id=1629 [21 de diciembre de 2007]

Larenz, K. (2001). Metodología de la Ciencia del Derecho. Barcelona: Ariel Derecho.

Menéndez Rexach, A. (1997). "La aplicación de la Ley 30/1992 a las entidades públicas empresariales”. En Vv. AA. Valoración de la Ley 30/1992 tras cinco años de vigencia. Madrid: Cuadernos de Derecho Judicial.

OssenbüHl, F. (1992). "Informe sobre la República Federal de Alemania. La Administración en la forma jurídica privada y a través de entidades privadas". Autonomies No 15.

Padrós Reig, C. (2001). Actividad administrativa y entidades colaboradoras. Madrid: Tecnos.

Rojas Calderón, C. (2008), "Los organismos autónomos y la Administración del Estado”. En Cordero Quinzacara, E. (Coordinador) Estudios sobre la Ley Orgánica Constitucional de Bases Generales de la Administración del Estado. Santiago: Universidad de Antofagasta.

Soto Kloss, E. (1986). "La organización de la Administración del Estado. Un complejo de personas jurídicas". Gaceta Juridica No 73.

SuñÉ Llinás, E. (1989). "Sobre el concepto de potestad". En Gómez Ferrer, Rafael (coordinación). Libro homenaje al profesor José Luis Villar Palasí. Madrid: Civitas.

TARrés Vives, M. (1998). "Los sujetos privados en la gestión y auditoría medioambiental comunitaria. Su desarrollo en la Umweltauditgesetz alemana". RAP No 145.

(2000). "Las nuevas referencias en el Derecho Industrial. Acreditación y normalización". Autonomies. Revista Catalana de Derecho Público, No 26.

(2003a). Normas técnicas y ordenamiento juridico. Valencia: Tirant lo Blanch.

(2003b). "Las normas técnicas en el Derecho Administrativo". Documentación Administrativa No 265-266.

Villar Palasí, J. L. (1950). "La actividad industrial del Estado en el Derecho Administrativo". RAP No 3. 
